\title{
Tocilizumab for patients with COVID-19 pneumonia. The single-arm TOCIVID-19 prospective trial
}

Francesco Perrone ${ }^{1 *} \mathbb{0}$, Maria Carmela Piccirillo ${ }^{1 \dagger}$, Paolo Antonio Ascierto ${ }^{2}$, Carlo Salvarani ${ }^{3}$, Roberto Parrella ${ }^{4}$, Anna Maria Marata ${ }^{5}$, Patrizia Popoli ${ }^{6}$, Laurenzia Ferraris ${ }^{7}$, Massimiliano M. Marrocco-Trischitta ${ }^{7}$, Diego Ripamonti ${ }^{8}$, Francesca Binda ${ }^{8}$, Paolo Bonfanti ${ }^{9}$, Nicola Squillace $^{9}$, Francesco Castelli ${ }^{10}$, Maria Lorenza Muiesan ${ }^{10}$, Miriam Lichtner ${ }^{11}$, Carlo Calzetti ${ }^{12}$, Nicola Duccio Salerno ${ }^{13}$, Luigi Atripaldi ${ }^{4}$, Marco Cascella ${ }^{14}$, Massimo Costantini ${ }^{15}$, Giovanni Dolci ${ }^{3}$, Nicola Cosimo Facciolongo ${ }^{15}$, Fiorentino Fraganza ${ }^{4}$, Marco Massari ${ }^{15}$, Vincenzo Montesarchio ${ }^{4}$, Cristina Mussini ${ }^{16}$, Emanuele Alberto Negri ${ }^{15}$, Gerardo Botti ${ }^{1}$,

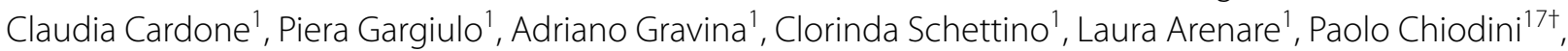
Ciro Gallo ${ }^{17 \dagger}$ and the TOCIVID-19 investigators, Italy

\begin{abstract}
Background: Tocilizumab blocks pro-inflammatory activity of interleukin-6 (IL-6), involved in pathogenesis of pneumonia the most frequent cause of death in COVID-19 patients.

Methods: A multicenter, single-arm, hypothesis-driven trial was planned, according to a phase 2 design, to study the effect of tocilizumab on lethality rates at 14 and 30 days (co-primary endpoints, a priori expected rates being 20 and $35 \%$, respectively). A further prospective cohort of patients, consecutively enrolled after the first cohort was accomplished, was used as a secondary validation dataset. The two cohorts were evaluated jointly in an exploratory multivariable logistic regression model to assess prognostic variables on survival.

Results: In the primary intention-to-treat (ITT) phase 2 population, 180/301 (59.8\%) subjects received tocilizumab, and 67 deaths were observed overall. Lethality rates were equal to $18.4 \%(97.5 \% \mathrm{Cl}: 13.6-24.0, P=0.52)$ and $22.4 \%$ (97.5\% Cl: $17.2-28.3, P<0.001)$ at 14 and 30 days, respectively. Lethality rates were lower in the validation dataset, that included 920 patients. No signal of specific drug toxicity was reported. In the exploratory multivariable logistic regression analysis, older age and lower $\mathrm{PaO} 2 / \mathrm{FiO} 2$ ratio negatively affected survival, while the concurrent use of steroids was associated with greater survival. A statistically significant interaction was found between tocilizumab and
\end{abstract}

\footnotetext{
${ }^{\dagger}$ Francesco Perrone, Maria Carmela Piccirillo, Paolo Chiodini and Ciro Gallo contributed equally to this work.

This article has been updated to correct the collaborators of the TOCIVID-19 investigators.

*Correspondence: f.perrone@istitutotumori.na.it

${ }^{1}$ Clinical Trial Unit, Istituto Nazionale Tumori, IRCCS, Fondazione G. Pascale,

Napoli, Italy

Full list of author information is available at the end of the article
} otherwise in a credit line to the material. If material is not included in the article's Creative Commons licence and your intended use is not permitted by statutory regulation or exceeds the permitted use, you will need to obtain permission directly from the copyright holder. To view a copy of this licence, visit http://creativecommons.org/licenses/by/4.0/. The Creative Commons Public Domain Dedication waiver (http://creativecommons.org/publicdomain/zero/1.0/) applies to the data made available in this article, unless otherwise stated in a credit line to the data. 
respiratory support, suggesting that tocilizumab might be more effective in patients not requiring mechanical respiratory support at baseline.

Conclusions: Tocilizumab reduced lethality rate at 30 days compared with null hypothesis, without significant toxicity. Possibly, this effect could be limited to patients not requiring mechanical respiratory support at baseline.

Registration EudraCT (2020-001110-38); clinicaltrials.gov (NCT04317092).

Keywords: COVID-19, Pneumonia, Coronavirus, Tocilizumab, IL-6, Phase 2, Mortality, Safety

\section{Background}

Pneumonia is the most frequent and serious complication of COVID-19, due to excessive host immune response causing an acute respiratory distress syndrome [1-5].

Interleukin 6 (IL-6) is a pro-inflammatory cytokine implicated in several rheumatic diseases and in the socalled cytokine release syndrome (CRS). Tocilizumab is a recombinant humanized monoclonal antibody, directed against the IL-6 receptor. It is indicated for treating severe rheumatoid arthritis, systemic juvenile idiopathic polyarthritis and severe cytokine release syndrome (CRS) induced by chimeric antigen receptor T-cells (CAR-T) [6, 7].

Chinese researchers treated 21 patients with severe or critical COVID-19 pneumonia with tocilizumab $400 \mathrm{mg}$ iv with efficacy in terms of reduction of oxygen requirement $(15 / 20)$, resolution of radiologic lung lesions (19/21), normalization of lymphocyte count $(10 / 19)$, and reduction of C-reactive protein levels $(16 / 19)$ [8]. These results prompted a randomised trial (tocilizumab vs control, ChiCTR2000029765).

On March 19th, 2020 during the ascending phase of the Italian breakout, we launched the TOCIVID-19 study, to describe the efficacy of tocilizumab while controlling the highly increasing off-label use of the drug.

\section{Methods}

TOCIVID-19, an academic multicenter clinical trial, was promoted by the National Cancer Institute of Naples and was approved for all Italian centers by the National Ethical Committee at the Lazzaro Spallanzani Institute on March 18th, 2020; two amendments followed on March 24th, 2020 and April 28th, 2020 [9]. The study is coordinated through the web-based platform managed by the Clinical Trial Unit of the promoting center.

\section{Study design}

330 patients were initially planned for the single-arm phase 2 study based on one-month lethality rate of $15 \%$ as null hypothesis, an alternative hypothesis for tocilizumab of $7.5 \%$ (i.e. halving the expected lethality rate),
99\% power and 5\% two-tailed alpha error. Taking into account about $20 \%$ of cases not eligible after registration 400 patients had to be enrolled. The initial calculation was based on March 10th daily report on Italian breakout, but data tumultuously accumulating between March 10th and April 15th clearly showed it was largely underestimated, and that adding an earlier outcome could be worthwhile. Thus, the April 24th amendment introduced 14-day lethality rate as co-primary endpoint, and the expected lethality rates (null-hypotheses) at 14 and 30 days were redefined at 2 and 35\%, respectively, based on data received from the Italian National Institute of Health [10]. Nonetheless we decided to leave the planned sample size unchanged since it still allowed $99 \%$ and $95 \%$ power to recognize $10 \%$ absolute reduction at 14 and 30 days, respectively, with a significance level of $2.5 \%$ for each co-primary endpoint. It is worth emphasizing that any change in the protocol was introduced before extracting mortality data from the database, i.e. not being aware of the number and timing of recorded deaths.

\section{Patients}

Patients hospitalized due to clinical/instrumental signs of pneumonia, and with real-time PCR diagnosed SARS$\mathrm{CoV}-2$ infection, were eligible for the phase 2 study if they had oxygen saturation at rest in ambient air $\leq 93 \%$ or required oxygen support or mechanical ventilation either non-invasive or invasive (intubated less than $24 \mathrm{~h}$ before registration). There was no limitation based on age and gender.

Patients were not eligible in case of known hypersensitivity to tocilizumab, known active infections or other clinical conditions that could not be treated or solved according to the judgment of the clinician and contraindicated tocilizumab, ALT/AST $>5$ times the upper limit of the normality, neutrophils count $<500 / \mathrm{mmc}$, platelets $<50.000 / \mathrm{mmc}$, bowel diverticulitis or perforation.

Informed consent for participation in the study could be oral if a written consent was unfeasible. However, if patients lack capacity to consent due to disease severity, and an authorized representative was not immediately available, treatment could be administered by the treating physician on her/his own responsibility. 


\section{Treatment}

Tocilizumab was administered at the dose of $8 \mathrm{mg} / \mathrm{kg}$ up to a maximum of $800 \mathrm{mg}$ per dose. Such dose is the same approved by FDA for the treatment of CRS following CAR-T therapy [6]. A second administration of tocilizumab (same dose) was allowed $12 \mathrm{~h}$ after the first one if respiratory function had not recovered, at discretion of the Investigator. Tocilizumab was supplied at no cost by Roche Italy. Due to the rapidly increasing request, a variable delay between the date of patient registration and drug availability at the clinical centers occurred. There was no contraindication for concomitant treatment of respiratory impairment; also, concomitant experimental antiviral treatment was allowed.

\section{Statistical analysis}

Primary analysis was performed in the intention to treat population (ITT), defined as all patients enrolled; a secondary analysis was done in the modified ITT (mITT) population with patients who had received at least one dose of the study drug. All the subjects enrolled by uncooperative centers, i.e. centers providing information on baseline characteristics and treatment for less than 25\% of their patients, were removed from any analyses. This amendment, in agreement with IDMC, was made blind to outcome data, i.e. before extracting mortality data.

Statistical analysis is detailed elsewhere [10]. Briefly, differences between groups of baseline characteristics, collected at the time of registration, are assessed for categorical variables using $x^{2}$ test and for continuous variables using Wilcoxon rank-sum test. Patients discharged to home or low-intensity care setting are considered alive at the end-date of the follow-up period of 30 days. Exact $97.5 \%$ Clopper-Pearson confidence intervals (CI) are calculated for the proportions of death at 14 and 30 days. Pre-specified null hypotheses at days 14 and 30 are tested by a two-sided binomial test with alpha level equal to 0.025 . Efficacy outcomes (with exact 95\% CI) are described in baseline subgroups defined by demographics and clinical variables and compared with exact $\chi^{2}$ test. Analyses were carried out using Stata version 14.0 (Stata Corp. College Station, TX, USA) and R version 3.6.1 (R Foundation for Statistical Computing, Vienna, Austria).

\section{Validation cohort}

Since the number of patients planned in the single-arm phase 2 design was quickly achieved in less than $24 \mathrm{~h}$, a second prospective cohort, involving eligible patients registered by participating centers in the five subsequent days, was added to the study to corroborate the main phase 2 findings. The analyses in this 'validation' cohort are to be considered secondary. The enrollment in the additional cohort was limited to five days because of the emerging drug shortage due to the huge request of drug by centers. The analyses performed in phase 2 were repeated in the validation cohort. For the sake of efficiency, the results of the validation cohort are reported side by side those of phase 2 .

\section{Joint cohort for safety analysis}

Analysis of safety was performed joining the two prospective cohorts and was limited to patients who received at least one dose of the study drug. Adverse events recorded from registration up to 30 days were graded according to CTCAE term (Version 5.0) and reported for each category and term as the worst grade suffered by patients through the whole period of observation after treatment administration.

\section{Exploratory multivariable analysis}

An exploratory multivariable logistic regression model was also performed in the combined cohort to assess prognostic variables on survival, that involved treatment with tocilizumab and/or corticosteroids [11], age $(\leq 60$, $61-70,>70$ ), gender, type of respiratory support (oxygen, non-invasive mechanical ventilation [NIMV], invasive mechanical ventilation $[\mathrm{IMV}]), \mathrm{PaO} 2 / \mathrm{FiO} 2$ ratio $(\leq 100$, 101-200,>200, missing/not evaluated), population (phase 2 or validation) and geographical area (Lombardia, Veneto, Emilia-Romagna, other Northern regions, Center, South and Islands) as covariates. To reduce immortal time bias, patients who received tocilizumab four or more days after registration were excluded from the analysis. The interaction effects between treatment and the other covariates were tested in turn one at a time by Wald test and retained in the final model only if significant. Difference in the lethality rate between treated and untreated patients was calculated within specific subgroups and $95 \%$ CI was calculated by means of Agresti and Caffo method [11]. Description of such differences must be considered as exploratory and hypothesis-generating only.

\section{Results}

\section{Single-arm phase 2 cohort}

From March 19th (at 14:00) to March 20th (at 12:45), 2020, 51 centers prospectively registered 402 patients for the phase 2 study (Fig. 1, left side), of which 2 cases were duplicated and one case withdrew consent. Ninetyeight patients enrolled by 12 uncooperative centers were removed from the analysis. Therefore, the phase 2 ITT population include 301 patients. Out of these, 21 were found ineligible a posteriori (12 intubated more than $24 \mathrm{~h}$ before registration, 7 registered after being already treated, 2 with both violations) but remained in the 


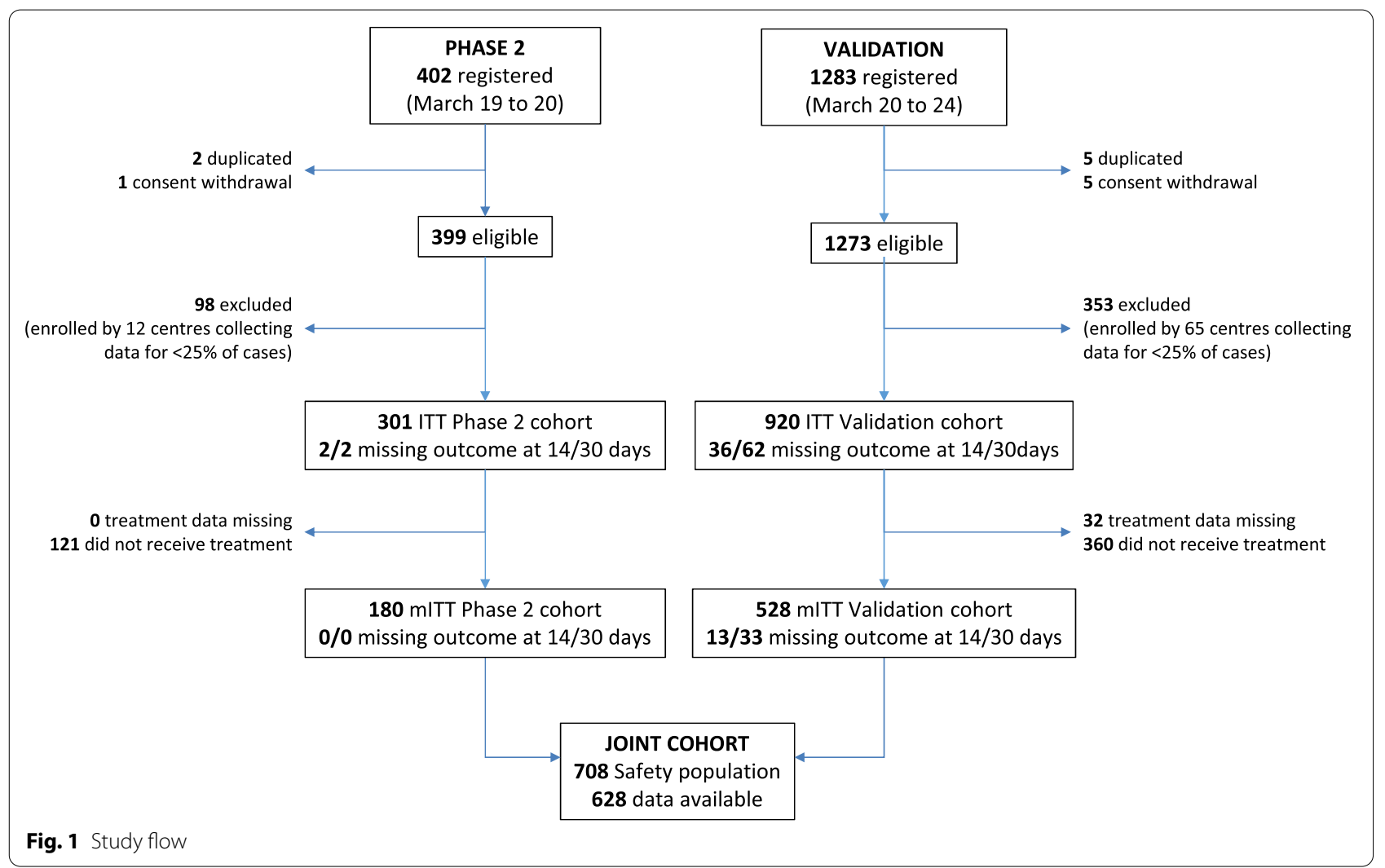

analysis. Geographical distribution and baseline characteristics of patients are summarized in Additional file 1: Figure S1 (top graphs), Table 1 (left side) and Additional file 1: Tables S1-3 (left side).

Due to lagged drug availability, treatment was given to $59.8 \%$ of patients. Median time from registration to treatment administration was 2 days; $23.3 \%$ of treated patients received tocilizumab four or more days after registration. The most frequent reason for not giving the drug (once available) was clinical improvement (Additional file 1: Table S4, left side). Patients who were younger, and those with worse respiratory function were preferentially treated; also, the geographic location of the center played a role (Table 2 , left side).

Overall, $67(22.3 \%)$ deaths were reported in the ITT phase 2 cohort. Lethality rate was $18.4 \%$ (97.5\% CI: 13.6-24.0) at 14 days and $22.4 \%$ (97.5\% CI: $17.2-28.3)$ at 30 days. The null hypothesis was rejected at 30 days but not at 14 days $(P<0.001$ and $P=0.52$, respectively). At both time points, lethality rates were lower in the mITT population (15.6\% and $20.0 \%$-Table 3, left side). Due to typical immortal time bias, lethality rates at 14 days were lower for patients receiving treatment four or more days after registration. Risk of death was significantly higher in patients older and with worse $\mathrm{PaO} 2 / \mathrm{FiO} 2$ ratio; in addition, lethality rates were lower for patients receiving concurrent corticosteroids, particularly at 14 days where the difference was statistically significant (Fig. 2 and Additional file 1: Table S5, left side).

\section{Single-arm validation cohort}

The validation cohort included 1273 patients enrolled by 211 centers from March 20th to March 24th, 2020 (Fig. 1, right side). Three hundred fifty-three patients enrolled from 65 uncooperative centers were removed, and 920 patients represented the ITT population. Baseline characteristics, shown in tables and figures side by side those of phase 2 patients, were more favorable in the validation than in the phase 2 cohort. Treatment compliance was similar (Additional file 1: Table S4, right side). Also in the validation cohort, available treatment was preferentially given to patients with worse respiratory function (Table 2, right side). Overall, 158 (17.2\%) deaths were reported in the ITT validation cohort. Probability of death was lower in the validation than in the phase 2 cohort, particularly among untreated patients (Additional file 1: Figure S2). In the validation cohort, lethality rates were consistently lower than the predefined null hypothesis both at 14 and 30 days in the ITT (11.4 and $18.4 \%)$ and mITT $(10.9 \%$ and $20.0 \%)$ populations (Table 3, right side). Subgroup analysis of lethality rates 
Table 1 Baseline characteristics of patients in the ITT phase 2 and validation cohorts

\begin{tabular}{|c|c|c|}
\hline & $\begin{array}{l}\begin{array}{l}\text { ITT Phase } 2 \\
\mathrm{~N}=301\end{array}\end{array}$ & $\begin{array}{l}\text { ITT Validation } \\
\mathrm{N}=920\end{array}$ \\
\hline \multicolumn{3}{|l|}{ Geographic area—no. (\%) } \\
\hline Lombardia & $136(45.2 \%)$ & $346(37.6 \%)$ \\
\hline Veneto & $65(21.6 \%)$ & $41(4.5 \%)$ \\
\hline Emilia Romagna & $37(12.3 \%)$ & $142(15.4 \%)$ \\
\hline Other Northern regions & - & $91(9.9 \%)$ \\
\hline Center & $39(13.0 \%)$ & $186(20.2 \%)$ \\
\hline South and Islands & $24(8.0 \%)$ & $114(12.4 \%)$ \\
\hline \multicolumn{3}{|l|}{ Age-no. (\%) } \\
\hline$\leq 60$ & $122(40.5 \%)$ & $375(40.8 \%)$ \\
\hline $61-70$ & $107(35.5 \%)$ & $263(28.6 \%)$ \\
\hline $71+$ & $72(23.9 \%)$ & $282(30.7 \%)$ \\
\hline Female sex-no. (\%) & $59(19.6 \%)$ & $200(21.7 \%)$ \\
\hline \multicolumn{3}{|l|}{ Ethnic group—no. (\%) } \\
\hline Caucasian & $271(97.1 \%)$ & $853(97.7 \%)$ \\
\hline Asiatic & $3(1.1 \%)$ & $2(0.2 \%)$ \\
\hline Other & $5(1.8 \%)$ & $18(2.1 \%)$ \\
\hline Unknown & 22 & 47 \\
\hline \multicolumn{3}{|l|}{ Body mass index-no. (\%) } \\
\hline Underweight/normal $(<25)$ & $75(28.8 \%)$ & $192(26.9 \%)$ \\
\hline Overweight/obese $(25+)$ & $185(71.2 \%)$ & $521(73.1 \%)$ \\
\hline Unknown & 41 & 207 \\
\hline Previous/actual smoker—No. (\%) & $51(22.2 \%)$ & $214(29.2 \%)$ \\
\hline Unknown & 71 & 188 \\
\hline Antiflu 2019 vaccination —No. (\%) & $54(25.0 \%)$ & $121(20.3 \%)$ \\
\hline Unknown & 85 & 325 \\
\hline \multicolumn{3}{|l|}{ Initial respiratory support—No. (\%) } \\
\hline Oxygen supplementation & $146(48.5 \%)$ & $468(50.9 \%)$ \\
\hline NIMV & $106(35.2 \%)$ & $359(39.0 \%)$ \\
\hline IMV & $49(16.3 \%)$ & $93(10.1 \%)$ \\
\hline $\mathrm{PaO} 2 / \mathrm{FiO} 2$ ratio-median (IQR) & $136(93,198)$ & $154(103,218)$ \\
\hline \multicolumn{3}{|l|}{$\mathrm{PaO} 2 / \mathrm{FiO} 2$ ratio-No. (\%) } \\
\hline$<100$ & $55(32.4 \%)$ & $129(24.1 \%)$ \\
\hline $101-200$ & $76(44.7 \%)$ & $244(45.5 \%)$ \\
\hline $201-300$ & $32(18.8 \%)$ & $116(21.6 \%)$ \\
\hline$>300$ & $7(4.1 \%)$ & $47(8.8 \%)$ \\
\hline Missing or not tested & 131 & 384 \\
\hline \multicolumn{3}{|l|}{$\begin{array}{l}\text { Comorbidities (mild or worse)—No. } \\
(\%)\end{array}$} \\
\hline Heart disease & $62(21.6 \%)$ & $150(18.1 \%)$ \\
\hline Hypertension & $147(51.2 \%)$ & $389(47.0 \%)$ \\
\hline Diabetes & $34(11.8 \%)$ & $138(16.7 \%)$ \\
\hline Unknown & 14 & 93 \\
\hline \multicolumn{3}{|l|}{ Concurrent treatment, no. (\%) } \\
\hline Antiretroviral & $180(63.1 \%)$ & $576(67.6 \%)$ \\
\hline Hydroxy-chloroquine & $207(72.6 \%)$ & $651(76.4 \%)$ \\
\hline Antibiotics & $118(41.4 \%)$ & $443(52.0 \%)$ \\
\hline Steroids & $62(21.8 \%)$ & $296(34.7 \%)$ \\
\hline LMW heparin & 66 (23.2\%) & 175 (20.5\%) \\
\hline
\end{tabular}

Table 1 (continued)

\begin{tabular}{cll}
\hline & $\begin{array}{l}\text { ITT Phase 2 } \\
\mathbf{N = 3 0 1}\end{array}$ & $\begin{array}{l}\text { ITT Validation } \\
\mathbf{N}=\mathbf{9 2 0}\end{array}$ \\
\hline $\begin{array}{l}\text { Unknown } \\
\text { C-reactive protein_median (IQR) }\end{array}$ & 16 & 68 \\
Missing or not tested & $187.6(14.7,120.0)$ & $36.3(13.7,137.0)$ \\
\hline
\end{tabular}

produced results similar to those seen in phase 2 (Additional file 1: Figure S3 and Table S5, right side).

\section{Safety analysis}

Safety analysis was done in 628/708 patients of the combined cohort who had received at least one dose of tocilizumab (Additional file 1: Table S6). At least one adverse event was reported in $40.8 \%$ of patients. Of note, 68 deaths $(10.8 \%)$ were categorized within adverse events scale. Causality between such deaths and treatment was described as possible only in one of the 35 cases of respiratory failure. All the other fatal adverse events were reported as unlikely or not related to treatment administration. Seven out of 8 fatal infections were specified as COVID pneumonia. Adverse events that may represent specific side effects of tocilizumab are allergic reactions [3 cases] and ALT or AST increase (reported in 10.5 and $9.1 \%$, respectively) that was severe (grade 3 or 4 ) in around $3 \%$ of cases.

\section{Hypothesis-generating multivariable analysis}

Results of the exploratory multivariable logistic regression analysis in the combined cohort are reported in Additional file 1: Table S7. Age and respiratory function measured by $\mathrm{PaO} 2 / \mathrm{FiO} 2$ ratio were independently significant prognostic factors; the use of corticosteroids was associated with a lower OR of death both at 14 (OR 0.36, 95\% CI: $0.21-0.62$ ) and at 30 days (OR 0.62, 95\% CI: $0.40-0.95)$. No significant interaction was found between the effect of tocilizumab and age, gender, $\mathrm{PaO} 2 /$ $\mathrm{FiO} 2$ ratio, geographic location and phase 2 vs validation cohorts; also, no interaction was found between the effect of tocilizumab and the use of corticosteroids. A significant interaction was found between treatment and required respiratory support, interaction test p-values being equal to 0.03 and 0.08 at 14 and 30 days, respectively. Specifically, treatment effect on lethality rates was larger among patients not requiring mechanical respiratory support within $24 \mathrm{~h}$ from registration with a OR equal to 0.37 (95\% CI: 0.18-0.74) and 0.50 (95\% CI: $0.27-$ 0.92 ) and absolute reductions equal to 7.7 and $6.2 \%$, at 14 and 30 days, respectively (Additional file 1: Figure S4). 
Table 2 Distribution of baseline characteristics of patients collected at registration by treatment administration

\begin{tabular}{|c|c|c|c|c|c|c|}
\hline & \multicolumn{3}{|l|}{ Phase 2} & \multicolumn{3}{|l|}{ Validation } \\
\hline & Treated $(n=180)$ & Not treated $(n=121)$ & $P$ & Treated $(n=528)$ & Not treated $(n=360)$ & $P$ \\
\hline Geographic area—no. (\%) & & & $<0.001$ & & & 0.30 \\
\hline Lombardia & $94(52.2 \%)$ & $42(34.7 \%)$ & & 195 (36.9\%) & $140(38.9 \%)$ & \\
\hline Veneto & $14(7.8 \%)$ & $51(42.1 \%)$ & & $28(5.3 \%)$ & $12(3.3 \%)$ & \\
\hline Emilia Romagna & $29(16.1 \%)$ & $8(6.6 \%)$ & & $76(14.4 \%)$ & $65(18.1 \%)$ & \\
\hline Other Northern regions & - & - & & $51(9.7 \%)$ & $40(11.1 \%)$ & \\
\hline Center & $23(12.8 \%)$ & $16(13.2 \%)$ & & $107(20.3 \%)$ & $61(16.9 \%)$ & \\
\hline South and Islands & $20(11.1 \%)$ & $4(3.3 \%)$ & & $71(13.4 \%)$ & $42(11.7 \%)$ & \\
\hline Age-no. (\%) & & & 0.04 & & & 0.22 \\
\hline$\leq 60$ & $79(43.9 \%)$ & $43(35.5 \%)$ & & 209 (39.6\%) & $156(43.3 \%)$ & \\
\hline $61-70$ & $67(37.2 \%)$ & $40(33.1 \%)$ & & $148(28.0 \%)$ & 107 (29.7\%) & \\
\hline $71+$ & $34(18.9 \%)$ & $38(31.4 \%)$ & & $171(32.4 \%)$ & 97 (26.9\%) & \\
\hline Female sex-no. (\%) & $31(17.2 \%)$ & $28(23.1 \%)$ & 0.20 & $108(20.5 \%)$ & $85(23.6 \%)$ & 0.26 \\
\hline Ethnic group—no. (\%) & & & 0.42 & & & 0.1 \\
\hline Caucasian & $170(97.1 \%)$ & $101(97.1 \%)$ & & $494(97.4 \%)$ & $333(97.9 \%)$ & \\
\hline Asiatic & $1(0.6 \%)$ & $2(1.9 \%)$ & & $2(0.4 \%)$ & $0(0.0 \%)$ & \\
\hline Other & $4(2.3 \%)$ & $1(1.0 \%)$ & & $11(2.2 \%)$ & $7(2.1 \%)$ & \\
\hline Unknown & 5 & 17 & & 21 & 20 & \\
\hline Body Mass Index—no. (\%) & & & 0.06 & & & 0.74 \\
\hline Underweight/normal & $40(24.7 \%)$ & $35(35.7 \%)$ & & $112(27.1 \%)$ & $73(26.0 \%)$ & \\
\hline Overweight/Obese & $122(75.3 \%)$ & $63(64.3 \%)$ & & $301(72.9 \%)$ & $208(74.0 \%)$ & \\
\hline Unknown & 18 & 23 & & 115 & 79 & \\
\hline Previous/actual smoker-no. (\%) & $33(22.4 \%)$ & $18(21.7 \%)$ & 0.89 & $130(30.2 \%)$ & $79(27.9 \%)$ & 0.52 \\
\hline Unknown & 33 & 38 & & 97 & 77 & \\
\hline Antiflu 2019 vaccination—no. (\%) & $31(21.5 \%)$ & $23(31.9 \%)$ & 0.10 & $75(21.8 \%)$ & $44(18.5 \%)$ & 0.33 \\
\hline Unknown & 36 & 49 & & 184 & 122 & \\
\hline Initial respiratory support- no. (\%) & & & 0.003 & & & $<0.001$ \\
\hline Oxygen supplement & $73(40.6 \%)$ & $73(60.3 \%)$ & & $223(42.2 \%)$ & $223(61.9 \%)$ & \\
\hline NIMV & $74(41.1 \%)$ & $32(26.4 \%)$ & & $238(45.1 \%)$ & $112(31.1 \%)$ & \\
\hline IMV & $33(18.3 \%)$ & $16(13.2 \%)$ & & $67(12.7 \%)$ & $25(6.9 \%)$ & \\
\hline $\mathrm{PaO} 2 / \mathrm{FiO} 2$ ratio- no. (\%) & & & 0.08 & & & $<0.001$ \\
\hline$\leq 100$ & $36(33.6 \%)$ & $19(30.2 \%)$ & & 91 (25.9\%) & $30(18.3 \%)$ & \\
\hline $101-200$ & $53(49.5 \%)$ & $23(36.5 \%)$ & & $170(48.4 \%)$ & $66(40.2 \%)$ & \\
\hline $201-300$ & $14(13.1 \%)$ & $18(28.6 \%)$ & & $68(19.4 \%)$ & $44(26.8 \%)$ & \\
\hline$>300$ & $4(3.7 \%)$ & $3(4.8 \%)$ & & $22(6.3 \%)$ & $24(14.6 \%)$ & \\
\hline Unknown & 73 & 58 & & 177 & 196 & \\
\hline Heart disease-no. (\%) & $31(17.8 \%)$ & $31(27.4 \%)$ & 0.053 & $99(19.4 \%)$ & $48(15.6 \%)$ & 0.17 \\
\hline Unknown & 6 & 8 & & 18 & 53 & \\
\hline Hypertension一no. (\%) & $92(52.9 \%)$ & $55(48.7 \%)$ & 0.49 & $242(47.5 \%)$ & $141(45.9 \%)$ & 0.67 \\
\hline Unknown & 6 & 8 & & 18 & 53 & \\
\hline Diabetes—no. (\%) & $23(13.2 \%)$ & $11(9.7 \%)$ & 0.37 & $84(16.5 \%)$ & $51(16.6 \%)$ & 0.96 \\
\hline Unknown & 6 & 8 & & 18 & 53 & \\
\hline Anti-retroviral—no. (\%) & $112(65.1 \%)$ & $113(60.2 \%)$ & 0.40 & $342(66.4 \%)$ & $224(69.4 \%)$ & 0.38 \\
\hline Unknown & 8 & 8 & & 13 & 37 & \\
\hline Hydroxy-chloroquine-no. (\%) & $130(75.6 \%)$ & $77(68.1 \%)$ & 0.17 & $395(76.7 \%)$ & $244(75.5 \%)$ & 0.70 \\
\hline Unknown & 8 & 8 & & 13 & 37 & \\
\hline Antibiotics-no. (\%) & $84(48.8 \%)$ & $34(30.1 \%)$ & 0.002 & $274(53.2 \%)$ & $163(50.5 \%)$ & 0.44 \\
\hline Unknown & 8 & 8 & & 13 & 37 & \\
\hline Steroids—no. (\%) & $41(23.9 \%)$ & $21(18.6)$ & 0.29 & $176(34.2 \%)$ & $115(35.6 \%)$ & 0.67 \\
\hline
\end{tabular}


Table 2 (continued)

\begin{tabular}{|c|c|c|c|c|c|c|}
\hline & \multicolumn{3}{|l|}{ Phase 2} & \multicolumn{3}{|l|}{ Validation } \\
\hline & Treated $(n=180)$ & Not treated $(n=121)$ & $P$ & Treated $(n=528)$ & Not treated $(n=360)$ & $P$ \\
\hline Unknown & 8 & 8 & & 13 & 37 & \\
\hline LMW heparin—no. (\%) & 45 & 221 & 0.14 & $116(22.5 \%)$ & $57(17.7 \%)$ & 0.09 \\
\hline Unknown & 8 & 8 & & 13 & 37 & \\
\hline C-reactive protein —-median (IQR) & $30(13-116)$ & $73(17-122)$ & 0.06 & $31(14-132)$ & $57(14-144)$ & 0.38 \\
\hline Unknown & 34 & 29 & & 102 & 128 & \\
\hline
\end{tabular}

Table 3 Efficacy analysis

\begin{tabular}{|c|c|c|}
\hline & Phase 2 & Validation \\
\hline \multicolumn{3}{|l|}{14 days intention-to-treat } \\
\hline No. of events/no. of patients at risk & $55 / 299$ & $101 / 884$ \\
\hline Lethality rate, \% (97.5\% Cl) & $18.4 \%(13.6-24.0)$ & $11.4 \%(9.1-14.0)$ \\
\hline$P$ value $(P 0=20 \%)$ & 0.52 & $<0.001$ \\
\hline \multicolumn{3}{|l|}{$\begin{array}{l}14 \text { days modified intention-to- } \\
\text { treat }\end{array}$} \\
\hline No. of events/no. of patients at risk & $28 / 180$ & $56 / 515$ \\
\hline Lethality rate, \% (95\% Cl) & $15.6 \%(10.6-21.7)$ & $10.9 \%(8.3-13.9)$ \\
\hline \multicolumn{3}{|l|}{30 days intention-to-treat } \\
\hline No. of events/No. of patients at risk & $67 / 299$ & $158 / 858$ \\
\hline Lethality rate, \% (97.5\% Cl) & $22.4 \%(17.2-28.3)$ & $18.4 \%(15.5-21.6)$ \\
\hline$P$ value $(P 0=35 \%)$ & $<0.001$ & $<0.001$ \\
\hline $\begin{array}{l}\text { Median time of death, days } \\
\text { (IQR) }\end{array}$ & $8(4-14)$ & $11(4-18)$ \\
\hline \multicolumn{3}{|l|}{$\begin{array}{l}30 \text { days modified intention-to- } \\
\text { treat }\end{array}$} \\
\hline No. of events/no. of patients at risk & $36 / 180$ & $99 / 495$ \\
\hline Lethality rate, \% (95\% Cl) & $20.0 \%(14.4-26.6)$ & $20.0 \%(16.6-23.8)$ \\
\hline
\end{tabular}

\section{Discussion}

The primary analysis of the single-arm phase 2 TOCIVID-19 cohort suggests that tocilizumab may reduce lethality at 30 days, although its impact at 14 days seems less relevant. The adverse event profile is consistent with other reports and did not generate clinically relevant warnings, possibly because of the severity of clinical symptoms related to the underlying pathologic condition. [12, 13] Interestingly, the exploratory multivariable analysis showed that the possible effect of tocilizumab might be greater among patients not requiring mechanical ventilation and might be independent of the effect of corticosteroids, that were associated with lower lethality rates, consistently with preliminary findings of the Recovery trial. [14] Further, we did not find an interaction between the effect of tocilizumab and the concurrent administration of corticosteroids, consistent with another recent report. [15].
In the light of the large percentage of untreated subjects $(40 \%)$ and the selection bias of treating patients with worse prognosis, these results support using tocilizumab while waiting for the publication of results of the phase 3 clinical trials. To our knowledge, six ongoing randomised trials are comparing tocilizumab vs placebo (ChiCTR2000029765, NCT04320615, NCT04381936, EudraCT 2020-001408-41, NCT04330638, NCT2020001767-86) and another one is comparing immediate vs delayed tocilizumab (NCT04346355). However, some trials have problems in reaching the planned sample size, and most of the trials on medical treatment of COVID19 are using non validated surrogate outcomes rather than mortality as primary end-point [16].

TOCIVID-19 is the largest completed prospective study on the effect of tocilizumab using mortality as primary end-point, among published or pre-published reports. Mostly, retrospective or observational data have been reported so far, not based on prospective hypothesis testing, with prevalently positive results [17-32].

However, our study has several limitations that deserve discussion for a better interpretation of findings. The main limitation is the single-arm study design, which prevents definitive conclusions [33]. We did that because, in our opinion, a randomised controlled trial was unfeasible in the middle of March 2020 in Italy. Indeed, there was a tremendous pressure to have the drug available, due to a widespread media diffusion of positive expectations and the increasing number of patients hospitalized for the disease, as confirmed by the massive registration of centers when the study began. Physicians' equipoise was poor, and obtaining a proper informed consent to randomization from patients was extremely difficult, because of clinical burden. Finally, developing a placebo was impossible, and, within a non-blinded study, the risk of cross-over from the control to the experimental arm would have been high, reducing the validity of the randomised trial. Within this context, the problem of "learning while doing" was increased, and we thought that the single-arm design was the best trade-off between dosomething and learn-something [34]. 


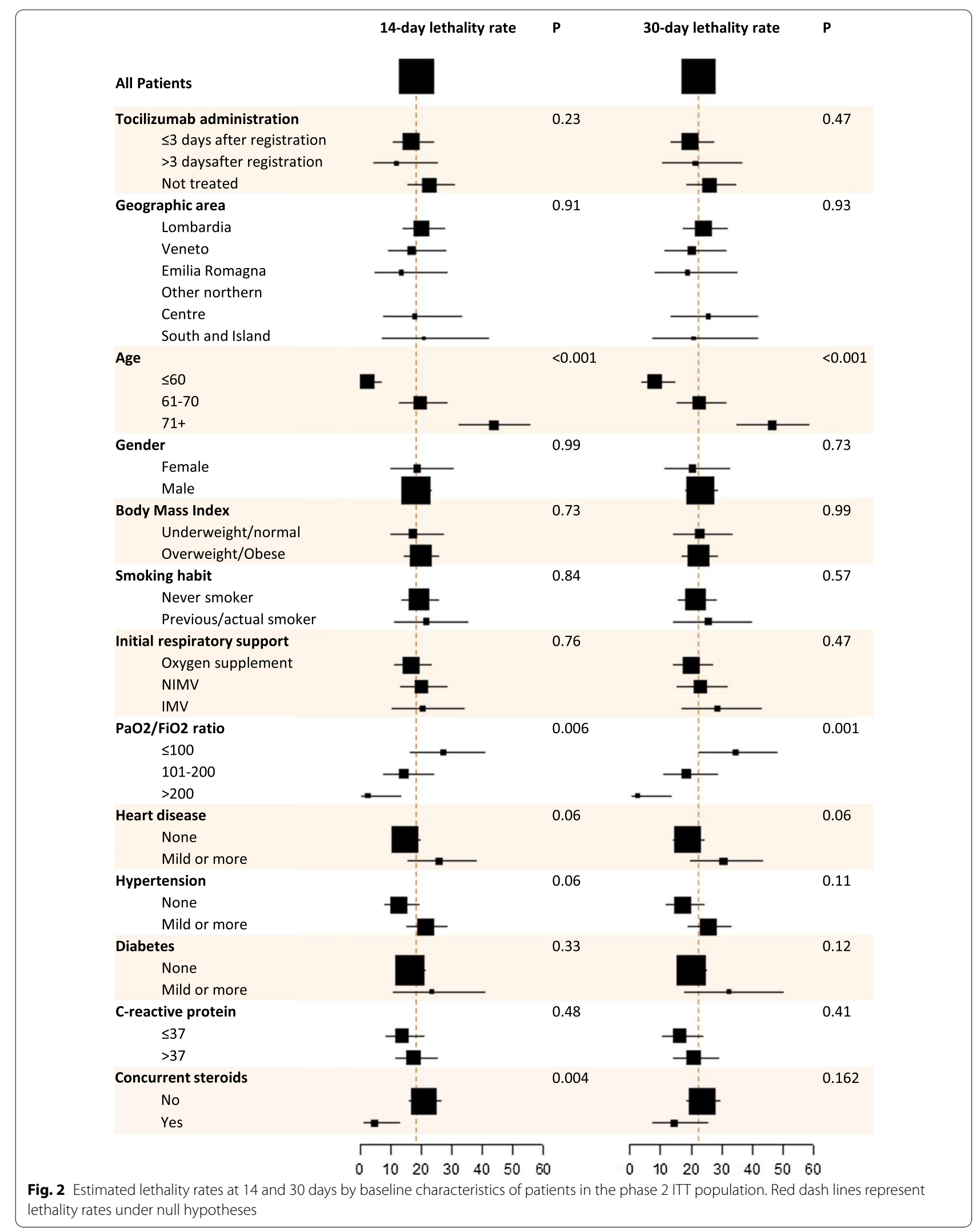


A critical issue of the single-arm design was the definition of the null hypotheses to be tested. We amended them following the evolving information from the National Institute of Health when we were blind to outcome data and in agreement with IDMC [10]. Yet, we cannot be sure that our assumptions are unbiased. A study with data on about 43.000 patients coming from three Italian regions, reports higher lethality at 14 days $(22.0 \%)$ and lower at 30 days (27.6\%) compared to TOCIVID-19 null hypotheses; assuming these estimates as a benchmark, our results would be still clinically significant at both 14 and 30 days [35].

Difference of survival experience between the two cohorts was unexpected. However, due to the exceptional setting in which the study was conducted, the validation cohort allowed the appreciation of the heterogeneity of the study population. Thus, combining cohorts in the multivariable evaluation seemed the most reasonable approach to explore prognostic factors while adjusting for the many confounding factors.

An operational problem of our study was the discrepancy between timing of drug availability (notwithstanding the commitment of the pharma company) and the extremely high request due to the rapid recruitment rate. Two contrasting biases followed in our study: the indication (selection) bias, when physicians opted for treating patients with worse prognosis, and the immortal time bias, when delay of treatment administration favored subjects surviving longer enough to receive the drug. As expected, the latter bias was particularly evident at 14-day analysis. To be conservative, we excluded from multivariable analyses all patients receiving the drug later than three days from registration, and adjusted for all available confounding factors, although some residual bias may still exist. Thus, findings of the multivariable analyses are to be considered hypothesis-generating only.

Last, we had many missing data, for several reasons: massive involvement and stress of physicians in emergency care; paucity or absence of data-managers; quarantine of paper charts; impracticality of peripheral monitoring; lack of training to the web platform; slow web connections for the study platform due to huge information loading volume. In agreement with IDMC, we reduced the problem by removing un-cooperative centers that provided baseline information for less than $25 \%$ of patients; however, we cannot be confident that the remaining missing data are at random.

TOCIVID-19 also has some strengths. As mentioned above, it is the first academic trial promoted in Italy, the largest in terms of centers and patients (being available for the whole Italian territory), assessing a hard endpoint like mortality in a hypothesis-driven design, while off label use of the drug was increasing. [36] In addition, the internal validation, allowed by a companion prospective cohort, contributed to critical interpretation of the results. Further analyses will focus on secondary outcomes (e.g. respiratory outcomes, predictive and prognostic factors, epidemiology insights) and on a larger number of patients.

\section{Conclusions}

Although with limitations of a single-arm study, performed in an extremely challenging time and environment, the present study supports the use of tocilizumab, even when corticosteroids are used, while waiting for publication of phase 3 results.

\section{Supplementary information}

Supplementary information accompanies this paper at https://doi.org/10. 1186/s12967-020-02573-9.

Additional file 1.TOCIVID-19_Appendix

\section{Acknowledgments}

List of participating centres and Co-Investigators

\section{TOCIVID-19 Investigators}

Istituto Nazionale Tumori, IRCCS, Fondazione G. Pascale, Napoli - Clinical Trials Unit: Francesco Perrone, Maria Carmela Piccirillo, Clorinda Schettino, Adriano Gravina, Piera Gargiulo, Claudia Cardone, Laura Arenare; Melanoma And Cancer Immunotherapy And Developmental Therapeutics Unit: Paolo Antonio Ascierto, Maria Grazia Vitale, Claudia Trojaniello, Marco Palla; Direction: Attilio Antonio Montano Bianchi, Gerardo Botti, Gianfranco De Feo, Leonardo Miscio. Università degli Studi della Campania Luigi Vanvitelli, Dipartimento di Salute Mentale e Medicina Preventiva; Ciro Gallo, Paolo Chiodini.

IRCCS Policlinico San Donato - Milano: Laurenzia Ferraris, Massimiliano M. Marrocco-Trischitta, Marco Froldi, Lorenzo Menicanti, Maria Teresa Cuppone, Giulia Gobbo, Chiara Baldessari, Vincenzo Valenti, Serenella Castelvecchio, Federica Poli, Francesca Giacomazzi, Rosangela Piccinni, Maria Laura Annnunziata, Andrea Biondi, Cecilia Bussolari, Manuel Mazzoleni, Andrea Giachi, Annalisa Filtz, Arianna Manini, Enrico Poletti, Federico Masserini, Francesco Conforti, Gianfranco Gaudiano, Vittoria Favero, Alice Moroni, Tommaso Viva, Fabiana Fancoli, Davide Ferrari, Dario Niro, Marco Resta, Andrea Ballotta, Marco Dei Poli, Marco Ranucci.

ASST Papa Giovanni XXIII - Bergamo: Diego Ripamonti, Francesca Binda, Alessandra Tebaldi, Giuseppe Gritti, Luisa Pasulo, Leonardo Gaglio, Roberto Del Fabbro, Leonardo Alborghetti.

ASST Monza - Monza: Paolo Bonfanti, Nicola Squillace, Giulia Giustinetti, Paola Columpsi, Marina Cazzaniga, Serena Capici, Luca Sala, Riccardo Di Sciacca,

Giacomo Mosca, Maria Rosa Pirozzi.

ASST degli Spedali Civili di Brescia e Università di Brescia - Brescia: Francesco Castelli, Maria Lorenza Muiesan, Franco Franceschini, Aldo Roccaro, Massimo Salvetti, Anna Paini, Luciano Corda, Chiara Ricci, Lina Tomasoni, Paola Nasta, Silvia Lorenzotti, Silvia Odolini, Emanuele Focà, Eugenia Quiros Roldan, Marco Metra, Stefano Magrini, Paolo Borghetti, Nicola Latronico, Simone Piva, Matteo Filippini, Gabriele Tomasoni, Francesco Zuccalà, Sergio Cattaneo, Francesco Scolari, Nicola Bossini, Mario Gaggiotti, Martina Properzi.

Ospedale Santa Maria Goretti - Latina: Miriam Lichtner, Emanuela Del Giudice, Raffaella Marocco, Anna Carraro, Cosmo Del Borgo, Raffaella Marocco, Valeria Belvisi, Tiziana Tieghi, Margherita De Masi, Paola Zuccalà, Paolo Fabietti, Angelo Vetica, Vito Sante Mercurio, Anna Carraro, Laura Fondaco, Blerta Kertusha, Ambrogio Curtolo, Emanuela Del Giudice, Riccardo Lubrano, Maria Gioconda Zotti, Antonella Puorto, Marcello Ciuffreda, Antonella Sarni, Gabriella Monteforte, Domenico Romeo, Emanuela Viola, Carla Damiani, Antonietta Barone, Barbara Mantovani, Daniela Di Sanzo, Vincenzo Gentili, Massimo Carletti, Massimo Aiuti, Andrea Gallo, Piero Giuseppe Meliante, Salvatore Martellucci, Oliviero Riggio, Vincenzo Cardinale, Lorenzo Ridola, Maria Consiglia Bragazzi, 
Stefania Gioia, Emiliano Valenzi, Camilla Graziosi, Niccolò Bina, Martina Fasolo Silvano Ricci, Maria Teresa Gioacchini, Antonella Lucci, Luisella Corso, Daniela Tornese, Parni Nijhawan, Francesco Equitani, Carmine Cosentino, Marcello Palladino, Frida Leonetti, Gaetano Leto, Camillo Gnessi, Giuseppe Campagna, Roberto Cesareo, Francesca Marrocco, Giuseppe Straface, Alessandra Mecozzi, Lidia Cerbo, Valentina Isgrò, Sergio Parrocchia, Giuseppe Visconti, Giorgio Casati.

AOU di Parma - Parma: Carlo Calzetti, Alarico Ariani, Lorenzo Donghi. AOUI di Verona - Verona: Nicola Duccio Salerno, Evelina Tacconelli, Marco Bertoldi, Paolo Cattaneo, Lorenza Lambertenghi, Leonardo Motta, Luca Omega. Humanitas Gavazzeni - Bergamo: Giovanni Albano.

AORN Dei Colli - Napoli: Roberto Parrella, Fiorentino Fraganza, Luigi Atripaldi, Vincenzo Montesarchio, Francesco Scarano, Annunziata De Rosa, Amalia Buglione, Sabrina Lavoretano, Gianfranco Gaglione, Mario De Marco, Vincenzo Sangiovanni, Francesco Maria Fusco, Rosaria Viglietti, Elio Manzillo, Carolina Rescigno, Raffaella Pisapia, Giulia Plamieri, Alberto Maraolo, Giosuè Calabria, Mario Catalano, Giuseppe Fiorentino, Anna Annunziata, Giorgio Polistina, Pasquale Imitazione, Mariano Mollica, Vincenzo Esposito, Maurizio D'Abraccio, Rodolfo Punzi, Vincenzo Bianco, Costanza Sbreglia.

Azienda Ospedaliera Umberto I - Siracusa: Rosa Fontana Del Vecchio, Alessandro Bordonali, Antonina Franco.

Arcispedale Santa Maria Nuova IRCCS - Reggio Emilia: Carlo Salvarani, Marco Massari, Giovanni Dolci, Pierpaolo Salsi, Matteo Fontana. ASST di Cremona - Cremona: Giuseppe Virzì, Calderone Ornella, Alfredo Molteni.

Azienda Ospedaliera San Salvatore - Pesaro: Silvia Gennarini, Umberto Gnudi, Maria Anastasia Ricci, Giancarlo Titolo, Giulio Mensi, Pietro Vuotto, Beatrice Gasperini, Mauro Mancini, Zeno Pasquini.

Ospedale Bassini - Cinisello Balsamo: Paolo Spanu, Stefano Clementi, Simona Pierini, Daniela Bokor, Daniela Gori, Morena Ciofetti, Marina Caimi, Laura Bettazzi, Elisabetta Allevi, Silvia Furiani, Chiara Capitanio, Bernardino Mastropasqua, Claudio Fara, Grazia Pulitanò, Jun Sebastian Matsuno, Francesca Della Porta, Viola Dolfini, Nebiat Balei Beyene.

ASST Degli Spedali Civili Di Brescia - Brescia: Michela Bezzi, Mauro Novali. AOU di Bologna - Bologna: Pierluigi Viale, Sara Tedeschi, Renato Pascale. Policlinico S. Matteo - Pavia: Raffaele Bruno, Alessandro Di Filippo, Michele Sachs, Tiberio Oggionni, Michele Di Stefano, Caterina Mengoli. Ospedale di Conegliano - Conegliano: Cesarina Facchini, De Nardo Daniele. Azienda Ospedaliera San Salvatore - Pesaro: Gabriele Frausini, Luciano Mucci, Silvia Tedesco, Rita Girolimetti, Elena Manfredini, Anna Maria Di Carlo, Emma Espinosa, Donatella Dennetta.

AOU di Parma - Parma: Andrea Ticinesi, Tiziana Meschi, Antonio Nouvenne. Azienda Ospedaliera Ordine Mauriziano - Torino: Norbiato Claudio, Francesco Vitale, Marta Saracco.

Ospedale Guglielmo Da Saliceto - Piacenza: Mauro Codeluppi, Elisa Fronti, Patrizia Ferrante.

Ospedale di Fermo - Fermo: Giorgio Amadio Nespola.

AOU di Perugia - Perugia: Daniela Francisci, Andrea Tosti.

Casa Sollievo Della Sofferenza - San Giovanni Rotondo: Cristiano Matteo

Carbonelli, Antonio Greco, Maria Giulia Tinti.

Fondazione Poliambulanza Istituto Ospedaliero - Brescia: Roberto Stellini, Camilla Appiani, Piera Reghenzi.

Ospedale Morgagni-Pierantoni - Forli: Venerino Poletti, Claudia Ravaglia. Ospedale Area Aretina Nord - Arezzo: Danilo Tacconi, Costanza Malcontenti. AOU "Maggiore della Carità" - Novara: Pier Paolo Sainaghi, Raffaella Landi, Veronica Vassia, Eleonora Rizzi, Mattia Bellan, Antonella Rossati, Luigi Castello Policlinico Umberto I - Roma: Claudio Maria Mastroianni, Gianluca Russo. Presidio Ospedaliero di Jesolo - Jesolo: Toffoletto Fabio, Francesco Saverio Serino, Lucio Brollo, Elena Momesso, Maria Luisa Turati. ASST Santi Paolo e Carlo - Milano: Antonella D’arminio Monforte, Giulia Marchetti.

Ospedale Civile di Guastalla - Guastalla: Fabrizio Boni, Elisabetta Teopompi, Chiara Trenti, Luca Boracchia, Enrica Minelli, Matteo Fontana, Giulia Ghidoni, Anaflorina Matei, Andrea Caruso.

AO Ospedali Riuniti Villa Sofia e Cervello - Palermo: Giuseppe Arcoleo, Gaetana Camarda, Filippo Catalano, Mario Spatafora.

Ospedale Sacra Famiglia, Fatebenefratelli - Erba: Donato Bettega.

AOU Policlinico Tor Vergata - Roma: Massimo Andreoni, Elisabetta Teti, Loredana Sarmati, Andrea Di Lorenzo, Mariagrazia Celeste.

Ospedali Riuniti Padova Sud - Padova: Fabio Baratto, Jacopo Monticelli, Pietro Criveller.
Ospedale San Paolo - Savona: Antonini Andrea, Anselmo, Riccio ASST Spedali Civili Di Brescia - Brescia: Maurizio Castellano, Carlo Cappelli, Federica Corvini, Barbara Zanini.

ASST Spedali Civili Di Brescia, Presidio Ospedaliero Gardone - Brescia: Massimo Crippa, Maurizio Ronconi, Raffaella Costa, Silvia Casella, Loretta Brentana. Ospedale Civile e Ospedale Dell'Angelo - Mestre: Livio Bernardi, Andrea Frascati, Sandro Panese, Fabio Presotto, Lucio Michieletto, Cristina Bernardi. Ospedale Santa Maria Delle Croci - Ravenna: Maurizio Fusar. Presidio Ospedaliero di Cesena - Cesena: Vanni Agnoletti, Martina Farina, Russo.

AOU Careggi - Firenze: Federico Lavorini, Roberta Ginanni.

Istituto Nazionale Malattie Infettive INMI L. Spallanzani, IRCCS - Roma: Fabrizio Palmieri, Silvia Mosti.

Casa Di Cura Beato Palazzolo - Bergamo: Angelo Amaglio, Alessandra Cattaneo.

Istituto Clinico S. Ambrogio Spa - Milano: Silvia Cirri, Andrea Montisci, Chiara

Gallazzi, Daniele Cosseta, Barabara Baronio, Lorenzo Rampa.

AO Sant'Anna e San Sebastiano - Caserta: Paolo Maggi, Vincenzo Messina.

Arcispedale Santa Maria Nuova IRCCS - Reggio Emilia: Emanuele Alberto Negri, Chiara Trenti.

Ospedale Generale Provinciale - Macerata: Marialma Berlendis, Maria Cecilia Sabatti.

Azienda Ospedaliera S.Maria - Terni: MichelePalumbo

ASST Ovest Milanese - Milano: Antonino Mazzone, Paola Faggioli.

Ospedale Bellaria - Bologna: Linda Bussini, Giacomo Fornaro, Francesca Volpato.

Ospedale Maria Vittoria - Torino: Daniele Imperiale, Emilpaolo Manno, Enrico Ferreri, Domenico Martelli, Andrea Verhovez, Silvia Giorgis, Luciana Faccio, Rachele Delli Quadri, Cristina Negro.

Ospedale Giovanni Bosco - Torino: Marcella Converso, Francesca Bosco. ASST Desenzano Del Garda - Gavardo: Silvia Amadasi, Paolo Prandini, Silvia Cocchi.

Azienda ULSS 6 - Vicenza: Vinicio Manfrin, Veronica Del Punta.

PO Sant'Elia - Caltanissetta: Giovanni Mazzola, Giuseppe Sportato.

Ospedale Ca' Foncello - Treviso: Micaela Romagnoli.

Ospedale Infermi - Rimini: Francesco Cristini, Francesca Facondini, Tiziana Perin, Andrea Boschi.

AOU di Modena - Modena: Cristina Mussini, Marianna Meschiari, Giovanni Guaraldi.

Presidio Ospedaliero San Luca - Lucca: Sara Modica, Sara Moneta, Daniela Boccalatte, Clara Ricci, Valentina Marchetti.

ASST Desenzano Del Garda - Ospedale Di Manerbio: Silvia Amadasi, Gabriele Ebbreo, Michael Dalè, Paolo Tura.

AO Spedali Civili, PO Montichiari - Brescia: Damiano Rizzoni, Gianluca Edoardo Mario Boari, Silvia Bonetti.

Ospedale San Liberatore di Atri - Teramo: Enrico Marini, Italiani Daniele. ASST Dei Sette Laghi - Varese: Paolo Antonio Grossi, Nichola Walter Delfrate. Ospedale Aziendale Di Bressanone - Bressanone: Othmar Bernhart, Gilbert Spizzo, Klaus Mahlknecht, Thomas Volkl.

Ospedale San Jacopo - USL Toscana Centro - Pistoia: Massimo Antonio Di Pietro, Michele Trezzi, Cecilia Monacci.

Ospedale di Rovigo - Rovigo: Adriano Peris, Manuela Bonizzoli.

Ospedale Guglielmo Da Saliceto - Piacenza: Luigi Cavanna, Carlo Moroni, Elisa Maria Stroppa, Alessandra Manini.

ASST Garda - Ospedale Civile La Memoria - Gavardo: Maria Cristina Savio, Francesca Gatti, Clara Bartolaminelli. Istituto Nazionale Malattie Infettive INMI L. Spallanzani, IRCCS - Roma: Nicola Petrosillo, Davide R. Donno, Fabrizio Taglietti, Simone Topino, Pierangelo Chinello, Vincenzo Galati.

Istituto Nazionale Malattie Infettive INMI L. Spallanzani, IRCCS - Roma: Gianpiero D'offizi, Chiara Taibi.

Ospedale Fiorentino - Firenze: Barbara Cimolato, Federico Moroni, Nicolas Palagano, Lorenzo Pelagatti, Seravalle Cristiana, Giancarlo Landini. Azienda Ospedaliera S. G. Moscati - Avellino: Maria Amitrano, Mariangela Raimondo, Sara Mangiacapra, Annamaria Romano, Mariangela Atteno. Ospedale S.M. Annunziata - AUSL Toscana Centro - Grassina: Pierluigi Blanc, Lorenzo Roberto Suardi, Carlo Pallotto

Ospedale F. Spaziani - Frosinone: Katia Casinelli, Ilaria Uccella. Ospedale S. Giuseppe - Milano: Sergio Harari, Antonella Caminati. Ospedale Amedeo Di Savoia - Torino: Filippo Lipani, Giovanni Di Perri, Andrea Calcagno, Guido Calleri, Chiara Montrucchio, Anna Maria Caputo. 
Presidio Ospedaliero S.Maria Del Carmine -Rovereto: Susanna Cozzio, Livia Delle Donne.

AO Policlinico Ospedale S. Martino - Genova: Matteo Bassetti, Mikulska Malgorzata, Laura Ambra Nicolini, Chiara Russo, Chiara Sepulcri, Sabrina Beltramini, Federica Mina.

ASST Grande Ospedale Metropolitano Niguarda - Milano: Massimo Puoti, Anna Gandino, Thomas Langer, Federico D'amico.

ASST Spedali Civili Di Brescia - Brescia: Marialma Berlendis, Chiara Rocchetti, Francesca Cettolo.

Presidio Ospedaliero Aziendale, AUSL Parma - Parma: Frausini Gabriele, Pietro Bocchi.

Ospedale Pavullo nel Frignano - Modena: Giorgio Cioni, Cinzia Cappi.

AOU Città della Salute e della Scienza - Ospedale Le Molinette - Torino:

Silvia Corcione, Francesco Giuseppe De Rosa, Silvia Scabini, Francesca Canta,

Simone Mornese Pinna, Anna Pensa.

Ospedale San Giuseppe - AUSL Toscana Centro - Empoli: Pierluigi Blanc, Lorenzo Roberto Suardi, Carlo Pallotto.

Azienda Ospedaliera Sant'Andrea - Roma: Monica Rocco, Maria Teresa Cirasa. AOU Careggi - Firenze: Michele Spinicci, Jessica Mencarini, Lorenzo Zammarchi.

Presidio Ospedaliero Unificato - San Remo: Cenderello Giovanni, Katiuscia Sciolè.

Presidio Ospedaliero Santa Maria della Misericordia - Udine: Flavio Bassi. Casa Di Cura S. Rita - Milano: Michele Bianchi, Sillia Frigerio.

Ospedale F. Spaziani - Frosinone: Sandra Spaziani, Antonia Nucera.

AO Luigi Sacco - Milano: Giuliano Rizzardini, Maria Vittoria Cossu, Marco Antivalle.

AOU Policlinico Vittorio Emanuele - Catania: Giuseppe Carpinteri.

Presidio Ospedaliero Riuniti - Reggio Calabria: Sebastiano Macheda, Demetrio Labate.

ASST Grande Ospedale Metropolitano Niguarda - Milano: Maurizio Bottiroli. Ospedale V. Fazzi - Lecce: Anacleto Romano.

Ospedale Generale Regionale - Bolzano: Elke Maria Erne, Zocchetti Cristina.

Ospedale Mazzini - Teramo: Valeria Di Biase.

ASST di Cremona - Cremona: Fabio Malberti, Alfredo Molteni.

ASST degli Spedali Civili di Brescia - Brescia: Giovanni Montani, Paolo Poisa,

Daniela Bettini.

Policlinico Universitario A. Gemelli - Roma: Roberto Cauda, Arturo Ciccullo.

Ospedale Sacro Cuore Don Calabria - Negrar (Verona): Niccolò Riccardi,

Andrea Angheben.

Ospedale Valduce Dous - Como: Mauro Turrini, Raffaella Clerici, Angelo Gardellini, Luigi Liparulo, Tizana Rossini.

PO SS. Annunziata - Chieti: Claudio Ucciferri, Francesco Cipollone, Jacopo Vecchiet.

Ospedale S.G. Moscati - ASL Taranto - Taranto: Andrea Nico, Lorenzo Marra, Armando Leone, Antonia Sdanganelli, Giuseppe Antonio Palmiotti, Giancarlo D'Alagni.

AOU Opsedali Riuniti - Foggia: Teresa Antonia Santantonio, Sergio Lo Caputo Irene Bottalico.

AO Sant'Anna e San Sebastiano - Caserta: Antonio Ponticiello, Felicia Di Perna. Ospedale Ca' Foncello - Treviso: Enrico Bernardi, Angela Beltrame, Stefania Bravi, Marco David, Paola Bernardi.

Ospedale G.Tatarella - Cerignola (Foggia): Dario Galante.

ASST Franciacorta - Presidio Ospedaliero di Iseo: Maria Cristina Uccelli, Katiela Prestini, Monica Drera, Enea Zini, Alessio Peregrinelli, Laura Blanzuoli.

Ospedale di Mondovì - ASL CN1 - Cuneo: Valentina Benedetti, Rovberta Calvi, Nadia Scaglione, Gabriella Nallino.

IRCCS Istituto Ortopedico Galeazzi Spa - Milano: Maurizio Bonazzi, Tiziano

Crespi, Tiziana Masolin.

Ospedale Delmati - Sant Angelo Lodigiano: Angelo Regazzetti, Maria Chiara Cerri, Elena Maffezzini, Manuela Piazza, Claudia Papetti, Claudia De Filippi, Elena Roveda, Giuseppe Cipolla, Mariano Scozzafava, Monica Crepaldi, Sonia Henchi, Nicolò Vanoni, Alice Repossi, Monia Vezzoli, Eva Scorletti, Orietta Perugini, Simone Marino Pasini, Veronica Pacetti, Luisella Ferrari, Giovanna Attilia de Paduanis, Sara del Duca, Francesca dell'Ara, Alessandra Brocchieri, Guja Minoja, Enrico Storti, Loredana Pitagora, Isabella Costa, Fanny Delfanti, Matteo Orlandi.

AO Ospedale Niguarda Ca Granda - Milano: Ruggero Ruggeri, Lorenzoa Ruggieri.

AO S. Giovanni Bosco - Torino: Sergio Livigni, Daniela Silengo.

AO Ospedale di Circolo e Fondazione Macchi - Varese: Walter Ageno.
Ospedale Bolognini - Seriate: Luciano Pedrini.

Ospedale Sant'Andrea - La Spezia: Stefania Artiol.

Ospedale Di Senigallia - Senigallia: Laura Morbidoni.

ASST di Mantova - Mantova: Giuseppe De Donno, Viviana Ravagnani, Francesco Inglese.

Ospedale Ca' Foncello - Treviso: Pier Giorgio Scotton.

Ospedale Civile Di Saluzzo - ASL CN1 - Cuneo: Paolo Costantini, Maurizio

Delucchi.

AOU di Modena - Modena: Enrico Clini.

Ospedale Di Senigallia - Senigallia: Andrea Ansuini.

Ospedale San Bassiano - Bassano Del Grappa: Baiocchi Marco, Lain Giuseppe.

Presidio Ospedaliero Aziendale AUSL Parma - Fidenza: Brianti Vincenzo, Gianni Rastelli.

AOU di Padova - Padova: Andrea Doria, Andrea Vianello, Anna Maria Cattelan, Sara Bindoli, Mara Felicietti.

ASST di Crema - Crema: Ciro Canetta, Alessandro Scartabellati, Silvia Accordino. PO Sant'Ottone Frangipane - Ariano Irpino: Maurizio Ferrara, Livio Cocco, Fernanda Cirillo, Erminio Pace, Monica De Caro, Marielisa Alberico, Giovanni Benigni, Terenzio Damiano, Pierluigi Fusco, Angela luorio, Giacomo Torretta. Ospedale S. Carlo Borromeo - Milano: Milena Racagni, Stefano Muttini. ASST della Valle Olona - Busto Arsizio: Girolamo Sala, Paolo Ghiringhelli. PO Maria SS. Addolorata - Eboli: Fernando Chiumiento, Laura Baccari. Arcispedale Santa Maria Nuova - Reggio Emilia: Enrica Minelli, Boracchia Luca, Federica Bocchi, Francesco Benatti, JacopoCatellani.

Ospedale di Belluno - Belluno: Marina Coppola.

AOU di Ferrara - Ferrara: Alberto Papi.

Ospedale di Conegliano - Conegliano: Enrico Bosco.

AO Universitaria Careggi - Firenze: Mnuela Bonizzoli, Chiara Lazzeri.

Ospedale Della Misericordia - Grosseto: Nencioni Cesira, Camilla Puttini, Tiziana

Carli, Leonardo Croci, Marta Corridi.

Ospedale di Stato di San Marino: Massimo Arlotti, Giulio Guerrini.

Presidio Ospedaliero Unico AV4 - Fermo: Luisanna Cola, Michela Romanelli.

AOU Ospedali Riuniti - Ancona: Marina Bonifazi, Stefano Gasparini, Federico

Mei, Elisabetta Cerutti.

AO Ospedali Riuniti - Foggia: Donato Lacedonia.

Istituto Clinico Humanitas - Rozzano: Armando Santoro, Giacomo Maria

Guidelli.

Ospedale Generale Provinciale - Saronno: Stefano Greco, Andrea Castellan,

Gessica Infantino, Laura Camici.

Ospedale S. M. Annunziata, AUSL Toscana Centro - Grassina: Francesca Covani Frigieri, Vittorio Pavoni

AOU Senese - Siena: Lucia Migliori, Barbara Rossetti, Francesca Montagnini.

PO Mauro Scarlato - Scafati: Immacolata Mauro, Elvira Genovese, Antonio

Capuozzo, Leonarda Vitiello, Emanuele Sirignano.

ASST della Franciacorta - Chiari: Paolo Gnesin.

AOU Federico II - Napoli: Giuseppe Servillo, Alfredo Marinelli.

AOU di Sassari - Sassari: Daniela Pasero, Lorenzo Casadio, Sergio Babudieri,

Giordano Madeddu, Andrea De Vito, Lorenzo Casadio, Melania Ranghitta.

ASST di Cremona - Cremona: Rodolfo Passalacqua, Fioravanti Antonio, Alfredo Molteni.

AOU Federico II -Napoli: Ivan Gentile, Antonio Riccardo Buonomo, Riccardo Scotto, Emanuela Zappulo.

AO S. G. Moscati - Avellino: Giuseppina Dell'Aquila.

Istituto Clinico S.Anna - Brescia: Angel Bianchetti, Fabio Guerini.

PO Jazzolino - Vibo Valentia: Alfredo Vallone, Peppino Oppedisano.

Ospedale Teresa Masselli Mascia Di San Severo - Foggia: Dario Galante.

Ospedale S. Anna - Como: Luigi Pusterla, Omar Giglio.

P.O. Maria SS. Addolorata - Eboli: Grazia Russo.

ASST degli Spedali Civili Di Brescia - Brescia: Enrico Sartori, Cristina Zanardini. Ospedale Sen. A. Perrino - Brindisi: Pietro Gatti, Valiani Vincenzo.

Ospedale Amedeo Di Savoia - Torino: Guido Calleri.

ASST di Lecco - Lecco: Stefania Piconi, Chiara Molteni.

ASST di Bergamo Ovest - Bergamo-Treviglio: Giuseppina Dognini.

Ospedale Castel San Giovanni, Covid Hospital - Piacenza-Castel San Giovanni:

Franco Cosimo.

PO Umberto I - Enna: Luigi Guarneri, Fabrizio Pulvirenti.

Stabilimento Ospedaliero Castelli - Verbania: Vincenzo Mondino, Gabriella Traballi.

Ospedale Fatebenefratelli E Oftalmico - Milano: Enrico lemoli, Antoenlla Grisolia, Riccardo Giorgi, Gabriella Nucera, Valentina Raffaelli, Pietro Marino, Enrica Negro, Lisa Serati, Tamanini Silvia 
AO per l'Emergenza Cannizzaro - Catania: Carmelo lacobello, Giuseppe Strano. Ospedale Sant'Andrea - Vercelli: Lucio Boglione.

Ospedale Regionale Umberto Parini - Aosta: Alberto Catania, Paola Gipponi. AO S.Maria - Terni: Luca Di Cato, Anna Panaccione.

Policlinico San Marco - Zingonia: Giovanni Vitale, Ilaria Alice Crippa, Matteo Giacomini.

AO Niguarda Ca Granda - Milano: Adriano Basile, Bellone Andrea.

Ospedale di Galatina S.Caterina Novella - Galatina: Paolo Tundo.

Ospedale Versilia - Camaiore: Stefano Buzzigoli, Gerardo Palmiero.

Ospedale Guglielmo Da Saliceto - Piacenza: Andrea Magnaca, Matteo Silva.

ASST Lecco - Merate: Massimo Ricci, Stefano Crespi, Bernadetta Pasquino.

Nuovo Ospedale Di Prato S. Stefano - Prato: Guglielmo Consales.

Casa Di Cura Privata - Peschiera Del Garda: Damiano Bragantini.

Ospedale Generale Regionale Miulli, Covid Hospital, Acquaviva Delle Fonti Bari: Franco Mastroianni, Giulia Righetti, Antonio Scarafino, Michele Bitetto. ASST della Valle Olona - Busto Arsizio: Fabio Franzetti.

Ospedale SS. Trinità - Cagliari: Sandro Piga.

Ospedale Generale Regionale Miulli, Acquaviva Delle Fonti - Bari: Vito Delmonte

Ospedale Bisceglie - Bisceglie: Sergio Carbonara, Ruggero Losappio.

Ospedale Aziendale Di Brunico - Brunico: Christian Dejaco

Policlinico Umberto I - Roma: Claudio Mastroianni, Gianluca Russo.

AO S. Croce e Carle - Cuneo: Valerio Del Bono.

Ospedale Santa Maria Bianca - Mirandola: Fabio Gilioli.

Ospedale Di Mirano - Mirano: Daniela Barzan, Silvia De Struppi.

Ospedale Alto Vicentino - Santorso: Antonio Carlotto, Maria Licia Guadagnin.

AOU di Modena - Modena: Massimo Girardis, Elisabetta Bertellini.

ASST dei Sette Laghi - Varese: Francesco Dentali.

PO Sant'Elia - Caltanissetta: Giancarlo Foresta.

Ospedale Apuane - Massa: Alberto Baratta, Rosangela Viviani.

ASST Grande Ospedale Metropolitano Niguarda - Milano: Antonio Maria

Agrati.

Istituto Auxologico Italiano - I.S. S.Luca - Milano: Giovanni Battista Perego.

AOU Policlinico - Vittorio Emanuele - Catania: Arturo Montineri, Rosa Manuele.

AO Gravina e S. Pietro - Caltagirone: Salvatore Bonfante.

Nuovo Ospedale Di Prato S. Stefano - Prato: Donatella Aquilini.

Complesso Ospedaliero A. Cardarelli - Campobasso: Alessandra Prozzo,

Donato Santopuoli, Zaira Di Rosa.

Policlinico San Pietro - Ponte San Pietro: Armando Alborghetti, Paolo Peci,

Nikoloz Bakhtadze, Chiara Stefania Pandini, Giovanni Casati, Najat Ashofarir.

AO Ospedale Niguarda Ca' Granda - Milano: Giampaolo Casella

Ospedale Di Trento - Trento: Walter Spagnolli, Silvana Urru, Ivan Marchesoni,

Giulia Caminiti

Istituto Clinica Città di Brescia - Brescia: Elena Argilloni, Elisabetta Danieli, Gianluca Ghirardi, Chiara Maria Antonioli, Alessio Lipari, Paola Zavarise, Francesco Kokaly.

AOUI Verona Borgo Trento - Verona: Enrico Polati, Leonardo Gottin

Presidio Ospedaliero Di Vittorio Veneto - Vittorio Veneto: Paolo Lucernoni,

Fabio De Conti, Elisabetta Marcon.

Ente Ospedaliero Ospedali Galliera - Genova: Emanuele Pontali, Elisabetta Blasi Vacca, Carolina Saffioti, Alessia Zunino.

AOU Ospedali Riuniti di Trieste - Trieste: Erik Roman Pognuz, Giorgio Berlot.

Ospedale Moscati - Taranto/Statte: Martino Saltori.

Ospedale Di San Bonifacio - San Bonifacio (VR): Andrea Tedesco.

ASST del Garda - Desenzano: Silvia Amadasi.

Ospedale di Treviso -Treviso: Carlo Agostini.

Ospedale Maggiore - Modica: Maria Antonietta Di Rosolini, Francesco Marino.

Istituto di Cura Città Di Pavia - Pavia: Guido Bellinzona.

Ospedale Carlo Urbani Di Jesi - Jesi: Walter Grassi, Marco Di Carlo.

Ospedale Maggiore Modica - Modica: Guglielmo Scimonello.

ASST Grande Ospedale Metropolitano Niguarda - Milano: Sandra Nonini, Michele Mondino.

Villa Maria Cecilia Hospital - Cotignola (RA): Lorenzo Filippo Mantovani, Elena Tenti.

ARNAS Garibaldi - Catania: Concetta Maria Gabriella Tropea, Daniela Emanuela Di Stefano.

Ospedale Privato Villalba Hospital: Paolo Guelfi.

IRCCS S. Raffaele - Milano: Lorenzo Dagna.

PO Gravina e S. Pietro - Caltagirone: Gianfranco Morgana.

ASST Grande Ospedale Metropolitano Niguarda - Milano: Lidia Montemurro.
AOUI Verona - Borgo Roma - Verona: Domenico Girelli, Ernesto Crisafulli, Alessio Maroccia.

ASST Grande Ospedale Metropolitano Niguarda - Milano: Alessandra Maria

Cemuschi.

Ospedale Gagliardi - Trecenta: Mara Bernasconi.

Ospedale Maggiore SS. Annunziata - Savigliano: Ugo Zummo.

\section{TOCIVID-19 Study Coordinators}

Istituto Nazionale Tumori, IRCCS, Fondazione G. Pascale, Napoli - Clinical Trials Unit: Valentina Barbato, Simona Bevilacqua, Gaetano Buonfanti, Giuliana Canzanella, Giovanni De Matteis, Manuela Florio, Marilena Martino, Maria Teresa Ribecco, Fiorella Romano, Alfonso Savio, Lucia Sparavigna: Melanoma And Cancer Immunotherapy And Developmental Therapeutics Unit: Marcello Curvietto.

IRCCS Policlinico San Donato - Milano: Michele Citarella.

ASST Papa Giovanni XXIII - Bergamo: Leonardo Alborghetti.

Humanitas Gavazzeni - Bergamo: Valeria Nava, Paola Maggioni, Marta Magni. AORN Dei Colli - Napoli: Chiara lommelli, Antonella Bianco.

Arcispedale Santa Maria Nuova IRCCS Di Reggio Emilia: Romina Corsini, LindaValli, Maria Paola Ruggieri.

ASST di Cremona - Cremona: Annalisa Mancini.

Azienda Ospedaliera San Salvatore - Pesaro: Tiziana Melica.

Policlinico S. Matteo - Pavia: Alessandra Ferrari, Daniela Cicognini, Mariangela Delliponti, Andrea Zuccarini, Silvia Ciani.

AOU di Parma - Parma: Davide Raffaeli

Ospedale Morgagni Pierantoni - Forli: Luca Donati.

ASST Santi Paolo e Carlo - Milano: Stefania Cannizzo.

Ospedale Civile Guastalla - Guastalla: Stefania Lui.

Arcispedale Santa Maria Nuova IRCCS di Reggio Emilia - Reggio Emilia:

Romina Corsini, Linda Valli, Maria Paola Ruggieri.

Ospedale Infermi Rimini: Luca Santini.

AOU di Modena - Modena: Enrica Roncaglia, Pasquale Mighali.

Ospedale Aziendale Di Bressanone - Bressanone: Frederik Eisendle.

Ospedale San Jacopo - USL Toscana Centro: Giulia Cerino

Ospedale Guglielmo Da Saliceto - Piacenza: Chiara Citterio, Camilla Di Nunzio.

ASST di Cremona: Annalisa Mancini.

Policlinico Universitario A.Gemelli - Roma: Silvia Lamonica.

Ospedale Sacro Cuore Don Calabria - Negrar (Verona): Silvia Resimini.

Ospedale Sant'Andrea - La Spezia: Giovanni Sarteschi.

Ospedale Di Belluno: Chiara Pavei.

AOU di Ferrara - Ferrara: Nicholas Battistini.

Ospedale Generale Provinciale - Saronno: Erika Gazzola.

ASST di Cremona - Cremona: Annalisa Mancini.

PO Jazzolino - Vibo Valentia: Marco Miceli.

ASST di Lecco - Lecco: Silvia Pontiggia.

ASST di Bergamo Ovest - Bergamo-Treviglio: Veronica Lonati.

Ospedale Regionale Miulli, Covid Hospital, Acquaviva Delle Fonti - Bari: Giusy Giannandrea.

Ospedale Maggiore - Modica: Claudio Sortino.

AOUI di Verona - Borgo Roma - Verona: Serena Ravani.

Ospedale Delmati - Sant'Angelo Lodigiano: Cristiano Uggeri.

Ospedale Regionale Umberto Parini - Aosta: Genny Jocollé, Cristina Baré.

\section{TOCIVID-19 Research Nurses}

IRCCS Policlinico San Donato - Milano: Irene Baroni, Daniele De Candia, Barbara Fiorini, Katiuscia Chierico, Francesca Romeo, Roberta Bottega, Laura Boccasile, Annamaria Corsaro.

Azienda Ospedaliera San Salvatore - Pesaro: Claudia Spadoni.

Ospedale Bassini - Cinisello Balsamo: Ria E Dipartimento Medico Ospedali Di

Sesto San Giovanni E Cinisello Balsamo.

ASST Spedali Civili Di Brescia: Silvia Chiari.

Azienda Ospedaliera S. G. Moscati - Avellino: Giovanna Ercolino.

Ospedale F. Spaziani - Frosinone: Vanessa Dell'uomo, Sabrina Viri.

Ospedale Ca'Foncello - Treviso: Milena Minato, Lisa Gazzola, Balan Dorina.

Ospedale Generale Provinciale - Saronno: Davide Gianelli.

ASST Franciacorta - Presidio Ospedaliero di Chiari: Sonia Maspero.

ASST della Valle Olona - Busto Arsizio: Maddalena Farinazzo.

INMI L. Spallanzani, IRCCS - Roma: Paola Zanini, Antonella Sangiovanni. 


\section{TOCIVID-19 Pharmacists}

Istituto Nazionale Tumori, IRCCS, Fondazione G. Pascale, Napoli - Clinical Trials Unit: Antonia Del Giudice.

IRCCS Policlinico San Donato - Milano: Maria Margherita Dragonetti, Susanna Bordignon.

ASST di Cremona - Cremona: Andrea Marco Machiavelli, Giulia Chiodelli,

Annalisa Mancini.

AORN Dei Colli - Napoli: Micaela Spatarella

Ospedale Bassini - Cinisello Balsamo: Davide Zenoni, Flavio Niccolò Beretta.

Ospedale Bellaria - Bologna: Giuseppina Santilli.

PO Sant'Elia - Caltanissetta: Rita Badagliacca.

AOU Careggi - Firenze: Manuela Angileri.

Azienda Ospedaliera S.G. Moscati - Avellino: Luciana Giannelli.

Ospedale Di Trento - Trento: Annalisa Campomori.

Ospedale Magalini - Villafranca di Verona: Patrizia Maimone.

Ospedale Regionale Umberto Parini - Aosta: Andrea Fadda.

Ospedali Riuniti Padova Sud - Padova: Sonia Faoro

AOU “Maggiore della Carità” - Novara: Alessia Pisterna

\section{Other TOCIVID-19 Investigators (centres enrolling patients after March \\ 24, 2020 only)}

Nuovo Ospedale Garibaldi Nesima - Catania: Bruno Cacopardo, Andrea

Marino, Alessio Pampaloni, Benedetto Maurizio Celesia.

AOU - Foggia: Gilda Cinnella, Daniela Labella, Rosa Roberta Caporusso.

Ospedale Magalini - Villafranca Di Verona; Maria Danzi, Marta Fiscon, Marina

Malena, Doris Fendt, Stefano Nardi.

AO SS. Antonio e Biagio Cesare e Arrigo: Paolo Stobbione, Maria Laura Savi.

ASST Melegnano e della Martesana: Andrea De Monte, Alberto Scala, Nicola Lucio Liberato.

Ospedale Apuane - Massa: Dr. Sauro Luchi; Sauro Luchi, Antonella Vincenti.

AO Ospedale di Circolo e Fondazione Macchi -Varese: Luca Cabrini.

AOU di Modena: Giovanni Pinelli.

AOU di Modena: Lucio Brugioni

Ospedale Brindisi Senatore. A. Perrino - Brindisi: Domenico Potenza. Ospedale S. Maria delle Grazie di Pozzuoli - Napoli: Fabio Giuliano Numis, Giovanni Porta, Maria D’amico, Bianca lengo.

AOU Consorziale Policlinico Bari: Gioacchino Angarano, Annalisa Saracino. ARNAS Ospedale Civico di Cristina Benfratelli - Palermo: Livio Blasi. Ospedale San Giuliano - Giugliano in Campania: Pasquale De Negri. Ospedale Di Fermo - Fermo: Stefano Angelici, Antonella Farina, Giuseppe Pio Martino, Giuseppina Bitti.

Ospedale Bolognini - Seriate: Alberto Tedeschi, Simona De Ponti.

Ospedale Civile Spirito Santo - Pesacara: Adriana Agostinone, Giustino Parruti, Augusta Consorte, Antonella Frattari.

AO San Giovanni di Dio e Ruggi d'Aragona- Salerno: Amelia Filippelli, Pasquale Pagliano, Alfonso Masullo, Carmine Sellitto.

Ospedale Maggiore Carlo Alberto Pizzardi - Bologna: Massimo Reta, Nicolò Rossi, Luigi Raumer.

Ospedale S. Maria Della Misericordia - Urbino: Silvia Andreassi, Paolo

Brancaleoni.

Ospedale San Francesco - Nuoro: Antonina Carai, Anna Maria Salerno.

Ospedale Civile S. Salvatore - L'Aquila: Franco Marinangeli, Roberta Mariani,

Antonello Ciccone.

Ospedale Morelli - Sondalo: Carlo Meschini, Gianluca Santoboni, Claudio Angrisani, David Micarelli, Giovanna Tarquini, Vittorio Fregoni.

AOU Di Ferrara: Carlo Alberto Volta.

Ospedale INRCA - Ancona: Antonio Cherubini, Maria Simona Del Prete, Erika

Ciarrochi.

Ospedale Di Montebelluna: Francesca Tasca, Andrea Ballarin, Andrea Bianchin. Ospedale A. Cardarelli - Campobasso: Romeo Flocco,Vincenzo Cuzzone.

Azienda Ospedaliera Umberto I -Siracusa: Maurilio Carpinteri.

Ospedale Di Belcolle - Viterbo: Carlo Meschini, Gianluca Santoboni, Claudio

Angrisani, David Micarelli, Giovanna Tarquini.

Istituto Clinico Beato Matteo Pietro - Vigevano: Pietro Gallotti.

Presidio Ospedaliero Ospedale Del Mare - Napoli: Federica Torre, Pio Zannetti.

AO S.M.A. Sede Di Pordenone: Massimo Crapis, Sergio Venturini

AO Santa Maria Nuova - Firenze: Massimo Barattini, Gianluca Gori.

PO Annunziata -Cosenza: Antonio Mastroianni.

Azienda Ospedaliera Regionale S. Carlo - Potenza: Giulio De Stefano, Michele Gilio.
Ospedale S. Camillo De Lellis - Rieti: Giuseppe Rapisarda, Leonardo Gulisano, Maria Luisa Granata, Sebastiana Saglimbene, Maria Teresa Montalto, Ilaria Grasso, Silvana De Luca, Gaetano Magro, Florinda Messina.

Ospedale Civile Di Ivrea: Bruno Scapino, Paolo Abrate, Chiara Francisco. Ospedale S. Luca - Vallo della Lucania: Laura Pesce.

PO S. Marta e S.Venera - Acireale: Giuseppe Rapisarda.

Ospedale Martini - Torino: Mauro Navarra.

ASST di Vimercate: Michele Agosti, Silvia Pagani, Martina Piluso, Aristodemo Ricioppo.

Ospedale Per Acuti Mater Salutis - Legnano: Silvia Tognella, Pierangelo Rovere, Marcello Vincenzi, Leonardo Ghirardi.

ASST di Cremona: Daniele Generali.

PO Mauro Scarlato -Scafati: Marco Ingrosso, Emilia Desiderio, Raffaele Molaro, Silvio Vitiello.

Ospedale Maggiore - Chieri: Alessandro Mastroianni, Luca Lancione, Tonia Celeste Paone, Alessandro Meli, Stefano Mainardi, Valentina Rastellino, Antonia Ursillo, Paola di Grigoli, Elena Bovetto, Ivana Marina Stefanetto, Francesca Mazzola.

Ospedale Ss Antonio E Margherita - Covid Hospital - Tortona: Antonio Daniele, Claudia Bisio, Pietro Delnero, Giovanni Morando, Antonella Nava, Lemut Francesco.

PO Gorizia eMonfalcone - Gorizia: Fabio Fiammengo, Monica Regis.

Ospedale San Giovanni Bosco - Torino: Dario Roccatello.

Ospedale Sen. A. Perrino - Brindisi: Eugenio Sabato.

Ospedale Civico - Chivasso: Marco Maria Liccardi, Cristina Bretto, Lorenzo Lutri, Enzo Castenetto

Presidi Ospedalieri Riuniti ASL.6 Ciriè - Torino: Giuseppe Roberti, Maria Francesca Guidi

ASST Rhodense - Rho: Francesco Bini.

Ospedale Sandro Pertini - Roma: Maria Crisitna Zappa, Tiziana Trequattrini, Rosario Rivitti, Rossana Vigliarolo, Angela Succu, Marianna Lilli, Mattia Serao, Giuseppina Giogré, Annamaria Ruggieri, Kristoffer Flores, Giuseppe Vairo, Roberto Satira.

Ospedale degli Infermi - Biella: Anna Lingua.

Ospedale San Giuseppe - Empoli: Rosario Spina.

Istituto Nazionale Malattie Infettive INMI L. Spallanzani IRCCS - Roma: Emanuele Nicastri, Gaetano Maffongelli, Filippo Barreca.

AOU Senese -Siena: Sabino Scollet, Federico Franchi, Camilla Fabbri.

Ospedale Policlinico - Verona: Pietro Minuz, Andrea Dalbeni.

AOU Integrata - Verona: Paolo Zanatta, Domenico Gelormini.

Presidio Ospedaliero V. Buzzi - Milano: Anna Mandelli, Feliciano Galderisi, Elena Zoia.

Ospedale di Schiavonia: Maria Rita Marchi, Naile De Almeida Neves.

Presidio Sanitario Gradenigo: Giorgio Carbone.

PO Boscotrecase: Emilio Di Caterino, Anna Petrone.

Ospedale S.S. Annunziata - Sassari: Carlo Andrea Usai, Francesco Bandiera.

Ospedale Civile Di San Candido: Roberto Monti, Alex Hofer.

AOU Policlinico Vittorio Emanuele - Catania: Giacomo Castiglione.

Ospedale Mazzini -Teramo: Chiara Angeletti.

Ospedale Ca'Granda Niguarda - Milano: Paolo Tarsia

Ospedale Maggiore - Chieri: Lorenzo Veronese, Paola Daniela Artoni.

Ospedale San Pietro Fatebenefratelli - Roma: Dora Larussa.

AO Ospedale Niguarda Ca Granda - Milano: Roberto Fumagalli, Paolo Brioschi.

Ospedale Santa Croce - Moncalieri: Alessandro Cerutti, Paola Pasquino, Fiore

Gilberto.

Presidio Ospedaliero Aziendale - Fidenza: Luca Cantadori.

ASST Spedali Civili - Brescia: Gabriele Tomasoni, Lina Rachele Tomasoni.

Azienda Universitaria Policlinico - Napoli: Nicola Coppola.

Ospedale di Borgo San Lorenzo: Stefano Spolveri, Costanza Pollastri, Lorenzo Fico

Madonna Del Soccorso - S. Benedetto:Tiziana Principi, Silvia Pierantozzi.

AO S.Giovanni/Addolorata - Roma: Col. Costantino Fontana

PO S. Francesco d'Assisi - Oliveto Citra: Giuseppe Lubrano.

Presidio Ospedaliero Alto Tevere - Città di Castello: Laura Martinelli, Stefano

Bravi

AOU di Padova - Padova: Paolo Navalesi, Eugenio Serra.

ASST Franciacorta: Paolo Gnesin, Enrico Cogi.

PO S. Maria Della Pietà - Nola: Andrea Manzi, Ermenegildo Furino.

Presidio Ospedaliero Di Chiari: Nicola Dasseni, Claudio Gentilini.

Ospedale B. Ramazzini - Carpi: Elisa Benatti, Andrea Pignatti.

Ospedale Civico - Partinico: Giuseppe Aiello, Mario Milia. 
AO Villa Scassi - Genova Sampierdarena: Maria Grazia Covesnon, Annalisa Brianti, Claudio Francesco.

Ospedale Di Mondovi CN1- Cuneo: Blangetti llaria.

Ospedale Civico - Chivasso: Fiammetta Pagnozzi, Sabrina Mietta.

Ospedale Pesenti Fenaroli - Alzano: Alberto Rossi

Ospedale S. Antonio Abate - Gallarate: Lorenzo Maroni, Vittorio Borroni, Claudio Bellintani.

Ospedale AULSS 15 Alta Padovana: Camilla Sgarabotto, Giada Bizzotto.

AO.Sant Anna E San Sebastiano - Caserta: Lucio Bucci.

AO Loreto Mare - Napoli: Giovanni Spagnuolo.

Ospedale Di Montebelluna: Moreno Agostini, Federico Carlo Caria, Filippo

Testa.

IRCCS AOU S. Martino - Genova: Raffaele De Palma, Giuseppe Murdaca.

Presidio Ospedaliero di Chiari: Gabriele Zanolini, Nadia Sala.

Ospedale Del Delta - Lagosanto: Erminio Righini.

IRCCS AOU S. Martino - Genova: Roberto Pontremoli.

Ospedale Moriggia Pelascini - Gravedona: Gianmarco Aondio.

AORN A. Cardarelli - Napoli: Ferdinando Riccardi; Ferdinando Riccardi, Maria Giovanna De Cristoforo, Fausto De Michele.

Azienda Ospedaliera S. G. Moscati - Avellino: Angelo Storti, Luciana Giannelli.

PO SS. Trinità - Cagliari: Roberto Perra, Silvia Deidda.

Azienda Ospedaliera Villa Scassi - Genova Sampierdarena: Caviglia Enrica,

Federico Valastro

ASST di Cremona: Matteo Giorgi Pierfranceschi, Fabio De Gennaro, Anna Laura Nardecchia, Alfredo Molteni.

ASST di Cremona; Mariateresa Castellini.

Ospedale San Pellegrino - Castiglione: Giovanni Buetto.

Casa Di Cura Policlinico - Monza: Giovanbattista Ippoliti.

Presidio Ospedaliero Di Arco: Domenico Sicheri.

Presidio Ospedaliero Oglio Po - Casalmaggiore: Maria Grazia Bottoli.

Ospedale di Vittorio Veneto: Blanca Martinez Lopez De Arroyabe, Alessandra Versaci.

Casa Di Cura Villa Pini Sanatrix - Civitanova Marche: Giada Pallotti.

Ospedale Civile E. Agnelli - Pinerolo: Marina Civita, Michele Grio, Nicola Liuzzi,

Paola Molino, Mauro Pastorelli, Alberto Ricchiardi, Ferdinando Varbella, Angela

Daniela Zeme.

Ospedale Madre Giuseppina Vannini - Roma: Cinzia Sighieri, Grazia Portale.

Casa Di Cura Villa Gemma - Gardone Riviera: Alessandro Olivetti, Carlo Pagnoni,

Greta Moschini, Sabrina Boni, Alberto Guerra, Roberta Scudellari, Sabrina Vella.

Presidio Ospedaliero Di Borgo Valsugana: Sandro Inchiostro.

PO S. Maria dell'Olmo - Cava de Tirreni: Ornella Piazza.

IRCCS Multimedica - Milano: Salvatore Guarino, Giorgio Aldegheri.

PO Paolo Borsellino - Marsala: Giovanna Napoli.

AOU Careggi - Firenze: Alessandro Morettini, Eleonora Caldini, Lorenzo

Menicacci.

AOU Careggi - Firenze: Filippo Pieralli, Monica Torrini.

AOU - Careggi - Firenze: Loredana Poggesi.

Clinica Pinna Pintor Srl - Torino: Enrico Maria Visetti.

Policlinico di Alessandria: Enrico Maria Visetti.

Presidio Ospedaliero Riuniti - Reggio Calabria: Carmelo Mangano.

Casa Di Cura Villa Barbarano - Salo: Stefano Visconti.

ASST di Bergamo Est: Pasquale Maietta.

Ospedale SS. Capitanio e Gerosa - Lovere: Elisa Banfi, Stefania Cartella.

Ospedale F. Spaziani - Frosinone: Bruna Venturi, Antonia Nuceri.

Ospedale San Pellegrino - Castiglione: Elena Chiesa, Enrico Pacentra.

Ospedale San Pellegrino - Castiglione: Gianluigi Panzolato.

AO Villa Scassi - Genova Sampierdarena: Michella Giannotti, Cristina Bianchi.

AOU di Modena: Antonello Pietrangelo.

AOU Careggi - Firenze: Ombretta Para, Maria Serena Rutili.

Presidio Sanitario Ospedale Cottolengo - Torino: Roberto Russo, Maurizio

Lanfranco, Elisa Scalabrino.

AOU Sant'Andrea - Roma: Agostino Tafuri.

Other TOCIVID-19 Study Coordinators (centres enrolling patients after March 24, 2020 only)

AO Villa Scassi - Genova Sampierdarena: Tosca Chiarello, Cristina Bianchi.

Ospedale degli Infermi - Biella: Elisa Perfetti.

Ospedale Di Montebelluna: Luca Cancanelli.

AORN A.Cardarelli - Napoli: Manuela Otero.

Casa Di Cura Villa Gemma - Gardone Riviera: Sabrina Vella, Greta Pannella,

Francesco Bellucci.
Presidio Sanitario Ospedale Cottolengo - Torino: Giovanna Ferrero.

AOU Sant'Andrea - Roma: Carmen Vico.

Ospedale Civile Spirito Santo - Pesacara: Maria Serafina Stillante.

Other TOCIVID-19 Research Nurses (centres enrolling patients after March 24, 2020 only)

Ospedale A.Cardarelli - Campobasso: Giovanna D'Andrea.

Ospedale S.Camillo De Lellis Rieti: Filippo Amoroso, Antonio Arcidiacono Anna Maria Bella, Agata Belsito, Ylenia Berté, Giulia Carubia, Maria Grazia

Caruso, Orazio Casella, Francesco Chiereleson, Chiara Costa, Daniela De Franco, Giuseppe Germanà, Antonio Messina, Diana Musumeci, Concetta Noto, Marco Valenti.

PO Mauro Scarlato - Scafati: Carlo Sorrentino, Rosanna Panico, Giuseppe Schettino, Jolanda Piccoli, Antonio Pepe, Francesco De Rosa, Mario Ottaviano,

Gerarda Marrazzo.

Ospedale Sandro Pertini - Roma: Gianna Raponi, Stefania Diberardino.

AOU Careggi - Firenze: Simona Bausi.

Presidio Sanitario Ospedale Cottolengo - Torino: Alessandro Ferrari.

OtherTOCIVID-19 Pharmacists (centres enrolling patients after March 24, 2020 only)

Ospedale SS Antonio E Margherita, Covid Hospital - Tortona: Sara Francesca

Marini.

Presidio Sanitario Gradenigo: Elena Giubellino, Giorgio Innocenti.

AORN A. Cardarelli - Napoli: Gaspare Gugliemi.

Ospedale di Vittorio Veneto: Daniela Maccari, Izabela Baciu.

Ospedale Maggiore - Chieri: Tonia Celeste Paone.

\section{Authors' contributions}

FP, MCP, PAA, CS, PC, CG designed the study. FP, MCP, GB, CCar, PG, AG, CS managed study conduction. CS, RP, AMM, PP, LF, MMMT, DR, FB, PB, NS, FC, MLM, ML, CCal, NDS, LA, MCa, MCo, GD, NF, FF, MM, VM, CM, EAN enrolled patients and collected study data. LA, PC, CG performed statistical analysis. FP, MCP, PC, CG wrote manuscript draft. All authors read and approved the final manuscript.

\section{Funding}

No specific funding was available for this study. Tocilizumab was provided by the pharmaceutical company (Roche) free of charge.

\section{Availability of data and materials}

The datasets used and/or analysed during the current study are available from the corresponding author on reasonable request.

\section{Ethical approval and consent to participate}

TOCIVID-19 was approved for all Italian centers by the National Ethical Committee at the Lazzaro Spallanzani Institute on March 18th, 2020 (registry number 22/2020). Informed consent for participation in the study could be oral if a written consent was unfeasible. However, if patients lack capacity to consent due to disease severity, and an authorized representative was not immediately available, treatment could be administered by the treating physician on her/ his own responsibility.

\section{Consent for publication}

Not applicable.

\section{Competing interests}

FP reports grants, personal fees and non-financial support from Bayer, personal fees from Sandoz, grants and personal fees from Incyte, personal fees from Celgene, grants and personal fees from Astra Zeneca, personal fees from Pierre Fabre, personal fees from Janssen Cilag, grants from Roche, grants from Pfizer, outside the submitted work.

MCP reports personal fees from Daichii Sankyo, personal fees from GSK, personal fees from MSD, grants from Roche, grants and personal fees from AstraZeneca, non-financial support from Bayer, outside the submitted work. PAA reports grants and personal fees from BMS, grants and personal fees from Roche-Genentech, personal fees and other from MSD, grants and personal fees from Array, personal fees from Novartis, personal fees from Merck Serono, personal fees from Pierre Fabre, personal fees from Incyte, personal fees from Genmab, personal fees from NewLink Genetics, personal fees from Medimmune, personal fees from AstraZeneca, personal fees from Syndax, personal 
fees from Sun Pharma, personal fees from Sanofi, personal fees from Idera, personal fees from Ultimovacs, personal fees from Sandoz, personal fees from Immunocore, personal fees from 4SC, personal fees from Alkermes, personal fees from Italfarmaco, personal fees from Nektar, personal fees from Boehringer-Ingelheim, outside the submitted work.

CS reports grants and personal fees from Roche, personal fees from SanofiGenzyme, personal fees from Abbvie, personal fees from Pfizer, personal fees from Lilly, personal fees from Novartis, outside the submitted work. FC reports grants from I am acting as Principal Investigator in company sponsored institutional clinical trials in the field of HIV (Gilead, ViiV, GSK, Janssen), HDV (Eiger) and coronavirus (Roche, Gilead), outside the submitted work. AG reports non-financial support from Pfizer, outside the submitted work. ML reports grants from Gilead, personal fees from Abbvie, personal fees from Merck, personal fees from Janseen, grants from Angelini, outside the submitted work.

The other Authors declare that they have no competing interests.

\section{Author details}

${ }^{1}$ Clinical Trial Unit, Istituto Nazionale Tumori, IRCCS, Fondazione G. Pascale, Napoli, Italy. ${ }^{2}$ Melanoma, Cancer Immunotherapy and Development Therapeutics Unit, Istituto Nazionale Tumori, IRCCS, Fondazione G. Pascale, Napoli, Italy. ${ }^{3}$ Rheumathology, Università degli Studi di Modena e Reggio Emilia and Azienda USL-IRCCS di Reggio Emilia, Modena, Italy. ${ }^{4}$ Cotugno Hospital, AORN Ospedali dei Colli, Napoli, Italy. ${ }^{5}$ Emilia Romagna Health Directorate, Bologna, Italy. ${ }^{6}$ Center for Drug Research and Evaluation, Istituto Superiore di Sanità, Roma, Italy. ${ }^{7}$ Infectious Diseases Unit, Hospital Health Direction, IRCCS - Policlinico San Donato, Milano Milano, Italy. ${ }^{8}$ Infectious Diseases Unit - ASST Papa Giovanni XXIII, Bergamo, Italy. ${ }^{9}$ Infectious Diseases Unit, ASST Monza and University Milano Bicocca, Milan, Italy. ${ }^{10}$ University of Brescia and ASST Spedali Civili, Brescia, Italy. ${ }^{11}$ Sapienza University of Rome, Santa Maria Goretti Hospital, Latina, Italy. ${ }^{12}$ Infectious Diseases and Hepatology Unit AOU, Parma, Italy. ${ }^{13}$ UOC Malattie Infettive e Tropicali, AOUI, Verona, Italy. ${ }^{14}$ Anesthesia and Resuscitation Unit, Istituto Nazionale Tumori, IRCCS, Fondazione G. Pascale, Napoli, Italy. ${ }^{15}$ Azienda USL-IRCCS di Reggio Emilia, Reggio Emilia, Italy. ${ }^{16}$ Università degli Studi di Modena e Reggio Emilia, Modena, Italy. ${ }^{17}$ Department of Mental Health and Preventive Medicine, Università degli Studi della Campania Luigi Vanvitelli, Caserta, Italy.

Received: 28 September 2020 Accepted: 13 October 2020 Published: 21 October 2020

\section{References}

1. Berlin DA, Gulick RM, Martinez FJ. Severe Covid-19. N Engl J Med. 2020. https://doi.org/10.1056/NEJMcp2009575.

2. Grasselli G, Zangrillo A, Zanella A, Antonelli M, Cabrini L, Castelli A, et al. Baseline characteristics and outcomes of 1591 patients infected with SARS-CoV-2 admitted to ICUs of the Lombardy Region Italy. JAMA. 2020;323(16):1574-81.

3. Guan WJ, Ni ZY, Hu Y, Liang WH, Ou CQ, He JX, et al. Clinical characteristics of coronavirus disease 2019 in China. N Engl J Med. 2020;382(18):1708-20.

4. Huang C, Wang Y, Li X, Ren L, Zhao J, Hu Y, et al. Clinical features of patients infected with 2019 novel coronavirus in Wuhan. China Lancet. 2020;395(10223):497-506.

5. Zhu N, Zhang D, Wang W, Li X, Yang B, Song J, et al. A novel coronavirus from patients with pneumonia in China, 2019. N Engl J Med. 2020;382(8):727-33.

6. Le RQ, Li L, Yuan W, Shord SS, Nie L, Habtemariam BA, et al. FDA approval summary: tocilizumab for treatment of chimeric antigen receptor $T$ cellinduced severe or life-threatening cytokine release syndrome. Oncologist. 2018;23(8):943-7.

7. Scott LJ. Tocilizumab: a review in rheumatoid arthritis. Drugs. 2017;77(17):1865-79.

8. Xu X, Han M, Li T, Sun W, Wang D, Fu B, et al. Effective treatment of severe COVID-19 patients with tocilizumab. Proc Natl Acad Sci U S A. 2020;117(20):10970-5.

9. Piccirillo M, Ascierto P, Atripaldi L, Cascella M, Costantini M, Dolci G, et al. Multicenter study on the efficacy and tolerability of tocilizumab in the treatment of patients with COVID-19 pneumonia. Contemp Clin Trials. 2020. https://doi.org/10.1016/j.cct.2020.106165.

10. Chiodini P, Arenare L, Piccirillo M, Perrone F, Gallo C. A phase 2, open label, multicenter, single arm study of tocilizumabon the efficacy and tolerability of tocilizumab in the treatment of patients with COVID-19 pneumonia (TOCIVID-19 trial): statistical analysis plan. Contemp Clin Trials. 2020. https://doi.org/10.1016/j.conctc.2020.100665.

11. Agresti A, Caffo B. Simple and effective confidence intervals for proportions and differences of proportions result from adding two successes and two failures. Am Statist . 2000;54(4):280-8.

12. Giacobbe DR, Battaglini D, Ball L, Brunetti I, Bruzzone B, Codda G, et al. Bloodstream infections in critically ill patients with COVID-19. Eur J Clin Investig. 2020;50:e13319.

13. Piano S, Dalbeni A, Vettore E, Benfaremo D, Mattioli M, Gambino CG, et al. Abnormal liver function tests predict transfer to intensive care unit and death in COVID-19. Liver Int. 2020. https://doi.org/10.1111/liv.14565.

14. Horby P, Lim WS, Emberson JR, Mafham M, Bell JL, Linsell L, et al. Dexamethasone in hospitalized patients with Covid-19_preliminary report. N Engl J Med. 2020. https://doi.org/10.1056/NEJMoa2021436.

15. Sanz Herrero F, Puchades Gimeno F, Ortega Garcia P, Ferrer Gomez C, Ocete Mochon MD, Garcia DM. Methylprednisolone added to tocilizumab reduces mortality in SARS-CoV-2 pneumonia: an observational study. J Intern Med. 2020. https://doi.org/10.1111/joim.13145.

16. Desai A, Gyawali B. Endpoints used in phase III randomized controlled trials of treatment options for COVID-19. EClinMed. 2020;23:100403.

17. Alattar R, Ibrahim TBH, Shaar SH, Abdalla S, Shukri K, Daghfal JN, et al. Tocilizumab for the treatment of severe coronavirus disease 2019. J Med Virol. 2020. https://doi.org/10.1002/jmv.25964.

18. Albertini L, Soletchnik M, Razurel A, Cohen J, Bidegain F, Fauvelle F, et al. Observational study on off-label use of tocilizumab in patients with severe COVID-19. Eur J Hosp Pharm. 2020. https://doi.org/10.1136/ejhph arm-2020-002414.

19. Antwi-Amoabeng D, Kanji Z, Ford B, Beutler BD, Riddle MS, Siddiqui F. Clinical outcomes in COVID-19 patients treated with tocilizumab: an individual patient data systematic review. J Med Virol . 2020. https://doi. org/10.1002/jmv.26038.

20. Biran N, Ip A, Ahn J, Go RC, Wang S, Mathura S, et al. Tocilizumab among patients with COVID-19 in the intensive care unit: a multicentre observational study. Lancet Rheumatol. 2020. https://doi.org/10.1016/S26659913(20)30277-0

21. Capra R, De Rossi N, Mattioli F, Romanelli G, Scarpazza C, Sormani MP, et al. Impact of low dose tocilizumab on mortality rate in patients with COVID-19 related pneumonia. Eur J Intern Med. 2020;76:31-5.

22. Colaneri M, Bogliolo L, Valsecchi P, Sacchi P, Zuccaro V, Brandolino F, et al. Tocilizumab for treatment of severe COVID-19 patients: preliminary results from SMAtteo COvid 19 REgistry (SMACORE). Microorganisms. 2020;8(5):695

23. Guaraldi G, Meschiari M, Cozzi-Lepri A, Milic J, Tonelli R, Menozzi M, et al. Tocilizumab in patients with severe COVID-19: a retrospective cohort study. Lancet Rheumatol. 2020;2(8):e474-84.

24. Jordan SC, Zakowski P, Tran HP, Smith EA, Gaultier C, Marks G, et al. Compassionate use of tocilizumab for treatment of SARS-CoV-2 pneumonia. Clinical Infect Dis. 2020. https://doi.org/10.1093/cid/ciaa812.

25. Klopfenstein T, Zayet S, Lohse A, Balblanc JC, Badie J, Royer PY, et al. Tocilizumab therapy reduced intensive care unit admissions and/or mortality in COVID-19 patients. Med Mal Infect. 2020;50(5):397-400.

26. Okoh AK, Bishburg E, Grinberg S, Nagarakanti S. Tocilizumab use in COVID -19 associated pneumonia. J Med Virol. 2020. https://doi.org/10.1002/jmv. 26471.

27. Petrak RM, Skorodin NC, Van Hise NW, Fliegelman RM, Pinsky J, Didwania $\checkmark$, et al. Tocilizumab as a therapeutic agent for critically III patients infected with SARS-CoV-2. Clin Transl Sci. 2020. https://doi.org/10.1101/ 2020.06.05.20122622.

28. Rojas-Marte G, Khalid M, Mukhtar O, Hashmi AT, Waheed MA, Ehrlich S, et al. Outcomes in patients with severe COVID-19 disease treated with tocilizumab: a case-controlled study. QJM. 2020;113(8):546-50.

29. Sciascia S, Aprà F, Baffa A, Baldovino S, Boaro D, Boero R, et al. Pilot prospective open, single-arm multicentre study on off-label use of tocilizumab in patients with severe COVID-19. Clin Exp Rheumatol. 2020;38(3):529-32. 
30. Toniati P, Piva S, Cattalini M, Garrafa E, Regola F, Castelli F, et al. Tocilizumab for the treatment of severe COVID-19 pneumonia with hyperinflammatory syndrome and acute respiratory failure: a single center study of 100 patients in Brescia, Italy. Autoimmun Rev. 2020;19(7):102568.

31. Zain Mushtaq M, BinZafarMahmood S, Jamil B, Aziz A, Ali SA. Outcome of COVID-19 patients with use of Tocilizumab: a single center experience. Int Immunopharmacol. 2020;88:106926.

32. Zhao J, Cui W, Tian BP. Efficacy of tocilizumab treatment in severely ill COVID-19 patients. Crit Care. 2020;24(1):524.

33. Goodman JL, Borio $L$. finding effective treatments for covid-19: scientific integrity and public confidence in a time of crisis. JAMA. 2020;323(19):1899-900.

34. Angus DC. Optimizing the trade-off between learning and doing in a pandemic. JAMA. 2020;323(19):1895-6.

35. Giorgi Rossi P, Ferroni E, Spila Alegiani S, Leoni O, Pitter G, Cereda D, et al. Survival of hospitalized COVID-19 patients in Northern Italy: a population-based cohort study by the ITA-COVID19 Network. MedrXiv. 2020. https://doi.org/10.1101/2020.05.15.20103119.

36. Addis A, Genazzani A, Trotta MP, Magrini N. Promoting better clinical trials and drug information as public health interventions for the COVID-19 emergency in Italy. Ann Intern Med. 2020. https://doi.org/10.7326/ M20-3775.

\section{Publisher's Note}

Springer Nature remains neutral with regard to jurisdictional claims in published maps and institutional affiliations.

- fast, convenient online submission

- thorough peer review by experienced researchers in your field

- rapid publication on acceptance

- support for research data, including large and complex data types

- gold Open Access which fosters wider collaboration and increased citations

- maximum visibility for your research: over 100M website views per year

At BMC, research is always in progress.

Learn more biomedcentral.com/submissions 